\title{
AERODYNAMIC LOADS ON A TYPICAL TENSION LEG PLATFORM
}

\author{
A. Kareem, ${ }^{*}$ P.C. Lu, ${ }^{*}$ T.D. Finnigan $\dagger$ and Shin-Lin V. Liu $\dagger$ \\ *Structural Aerodynamics and Ocean System Modeling Laboratory, University of Houston, Houston, TX \\ 77004, and †Chevron Corporation, San Ramon, CA, 94583-0945, U.S.A.
}

\begin{abstract}
The wind load effects on tension leg platforms have been recognized to be a significant environmental loading. An accurate assessment of the aerodynamic loads is, therefore, a prerequisite for the design of an economic and a reliable structure. The design codes and specifications recommend the use of a projected area approach that is thought to be conservative. The code recommendations fail to quantify aerodynamically induced forces in directions different to the mean wind flow. The interference and shielding effects suggested in some specifications provide only a simplistic view. Physical modeling as reported in this paper, therefore, continues to serve as the most accurate and practical means of predicting aerodynamic loads.

The mean aerodynamic force and moment coefficients of a typical tension leg platform for various approach wind directions were measured on a scale model exposed to simulated flow conditions in a boundary layer wind tunnel. Major components on the upper deck of the model were designed for easy removal so that measurements could be obtained for different platform configurations. A parametric study was conducted to determine shielding and interference effects, i.e. the manner in which aerodynamic coefficients are influenced by the location and orientation of the ancillary structures on the platform, e.g. living quarters, flare boom, derricks, etc. The present paper addresses the wind tunnel modeling procedures and automated data acquisition and reduction methods. The aerodynamic force and moment coefficients with respect to the body and flow axes were reduced from the experimental measurements for azimuth angles of 0 to 360 degrees at 15 -degree intervals. A total of eight configurations were monitored ranging from a platform configuration that included all the ancillary structures to the case where every deck component was removed. The aerodynamic coefficients obtained from the classification society recommended procedures provided conservative estimates in comparison with the measured values for all configurations. The results also illustrate that the interference effects among various ancillary structures on the platform are significant.
\end{abstract}

\section{INTRODUCTION}

WIND loads contribute significantly to the overall design loads for tension leg platforms (TLPs). Wind effects on these platforms consist of a mean and a fluctuating component. The mean wind effects result from mean wind force that can be computed from the mean wind velocity and an appropriate aerodynamic force coeffic nt. The fluctuating component results from the buffeting action of wind gusts or flow-induced effects. The compliant behavior of TLPs in the horizontal plane increases their sensitivity to dynamic effects of wind, which contain a significant level of energy in the low frequency range, that makes them susceptible to dynamic effects of wind. This leads to a relative increase in the overall sensitivity and strength requirements of compliant structures to wind loads compared to those of conventional fixed structures. 
The mooring system of a TLP resists the mean environmental forces, while jacket inertia resists short period loads. Therefore, the mooring system of TLPs, which consists of vertical tubular tension members, must be designed for steady winds, currents and wave-induced low frequency load effects.

The superstructure of a TLP has a complex geometry consisting of production and drilling equipment, living quarters and a helideck. The information available in design codes and specifications to determine aerodynamic force coefficients on offshore platforms has been limited to experimental data obtained from simplified wind tunnel models of basic structural shapes and configurations. Generally the synthesized force coefficient of a platform derived from code recommended values using a projected area approach are conservative. The level of conservatism depends on the structural geometry, aspect ratio and the approach flow characteristics. The problem of accurate prediction is complicated by the presence of complex three-dimensional vertical flow structures that originate from the flow separation on the windward region and engulf the entire structure. The complex phenomena of interference and shielding among members of the platform superstructure further complicates synthesis of overall load effects following a superposition procedure. A typical example is a vertical force component induced on a flat surface, e.g. helideck or living quarters, that contributes to the pitching moment. Physical modeling of these platforms, using scale models exposed to simulated atmospheric flow over the oceans in a boundary layer wind tunnel, therefore, continues to serve as an accurate and practical means of predicting aerodynamic loads. During physical modeling in a wind tunnel, any possible interaction between wind, structure and conceivably sea surface, as well as flow induced lift forces, shielding, interference, and the effects of finite aspect ratios of structural component can be determined for a particular TLP configuration.

A program of wind tunnel investigation to determine the mean aerodynamic force coefficients and to better understand the aerodynamics of tension leg platforms was undertaken and reported in this paper.

\section{REPRESENTATION OF WIND VELOCITY FIELD}

The wind velocity at a given point in space is taken to be the sum of the mean wind speed and the fluctuating component over a suitable period of time described by the standard deviation. As with the flow of any fluid over a surface, a boundary layer is developed in which the wind speed decreases from a maximum value to zero at the surface. A limited amount of data is available from wind measurements taken over the ocean and published results are uncertain, especially when extrapolated to extreme design conditions. The problem is essentially due to the practical difficulty of taking measurements which are compounded by the variable nature of the sea surface which translates and deforms. If the wind flow field and its characteristics are not significantly influenced by the exact form of the surface, but by the energy loss and rate of momentum transfer due to surface friction, the relationship established for the wind characteristics over land may also be applicable over the sea surface.

Accordingly, the description of the mean wind speed in a turbulent wind field is therefore assumed to be one of two forms (Kareem, 1980, 1985; Simiu and Scanlan, 1978). The first is the logarithmic law 


$$
\bar{U}(\mathrm{z})=\frac{\bar{U}_{10} \ln \frac{z}{z_{0}}}{\ln \frac{10}{z_{0}}}
$$

in which $\bar{U}_{10}=$ reference wind velocity at $10 \mathrm{~m} ; z=$ the vertical coordinate from the mean sea surface; and $z_{0}=$ roughness length. The second form is an empirical expression represented by a power law

$$
\bar{U}(\mathrm{z})=\bar{U}_{10}\left(\frac{z}{10}\right)^{\alpha}
$$

in which $\alpha=$ power-law exponent. The power-law profile has been widely used in many design codes and classification societies because of its simplicity (DnV, 1982). The value of $\alpha$ is dependent on the sea surface roughness and can be expressed in terms of $u_{*}$, friction velocity, and $z_{0}$, roughness length. The United States Geological Survey (1979) suggests the following wind profile.

$$
\bar{U}(z)=\bar{U}_{10}\left(\frac{z-2.2}{7.8}\right)^{0.1128}
$$

The Det norske Veritas (DnV) recommends $\alpha=0.15$ for the mean hourly wind velocity, whereas American Bureau of Shipping (ABS) recommends a uniform wind speed for every $50 \mathrm{ft}$ segment with a step increase with height from the mean sea surface (ABS, 1980). It is customary to express the relationship between wind shear stress and velocity at a point $Z$ by the wind stress coefficient. More detailed description of wind stress coefficient is given by Kareem (1985).

\section{AERODYNAMIC LOADS}

The aerodynamic force on a structure can be expressed in terms of the wind velocity and aerodynamic force coefficients

$$
\begin{aligned}
F_{i} & =1 / 2 \rho C_{a_{i}} A_{i} U^{2}\left(z_{\mathrm{ref}}\right), \\
\rho & =\text { air density }, \\
C_{a_{i}} & =\text { aerodynamic force coefficient, } \\
A_{i} & =\text { projected area, and } \\
U\left(z_{\mathrm{ref}}\right) & =\text { wind velocity at reference height. }
\end{aligned}
$$

The aerodynamic force results from the interaction of the wind with the superstructure (above water) of the platform which acts as a complex bluff configuration. Most of the windward surfaces experience positive pressure, whereas the side and the leeward surfaces experience negative pressure. The synthesis of pressure acting on the entire superstructure results in aerodynamic forces. The complexity of the aerodynamics of bluff structures with unusual configurations in boundary layer flows has hindered the development of analytical procedures for calculating aerodynamic forces. Therefore, 
physical modeling of scale models exposed to simulated atmospheric flow in a wind tunnel continues to serve as the most accurate and practical means of predicting aerodynamic loads. The aerodynamic loads determined experimentally using scaled models are expressed as nondimensional force and moment coefficients, namely

$$
\begin{aligned}
C_{a_{i}} & =\frac{F_{i}}{\frac{1}{2} \rho A_{i} U^{2}\left(z_{\mathrm{ref}}\right)} \\
C_{M_{i}} & =\frac{M_{i}}{\frac{1}{2} \rho A_{i} L_{i} U^{2}\left(z_{\mathrm{ref}}\right)}
\end{aligned}
$$

in which $L_{i}$ is a reference length.

Alternatively, aerodynamic force coefficients may be estimated using procedures given by specification societies, e.g. ABS and DnV. Essentially these procedures involve the synthesis of component forces based on the respective component force coefficients. Consequently, the platform force coefficient is obtained from the overall force by nondimensionalizing according to Equation (5). This approach is also referred to in the literature as a projected area approach. The problems of the accurate prediction of the complex phenomena of interference and shielding among the components of the superstructure limits the reliability of a projected area technique.

\section{EXPERIMENTAL PROGRAM}

In this study the mean force and moment coefficients of the above-water superstructure of a typical tension leg platform were measured for various approach wind directions. A parametric study was conducted to determine the manner in which these coefficients are influenced by the location and orientation of the ancillary structures on the platform, e.g. flare boom, mud house and derricks. The measured values were compared with force coefficients obtained by synthesizing component shape coefficients based on their respective projected areas. These comparisons may provide helpful guidance in the identification and subsequent quantification of interference and shielding effects.

A flow visualization study was carried out to facilitate a better understanding of the flow field around the platform. The visualization of the flow field helped to suggest areas on the platform that needed changes in the flow conditions. These improved flow conditions could be achieved through modifications in structural geometries or through the introduction of aerodynamic appendages. A summary of these tasks and important findings is given in this paper following a brief review of the rudiments of wind engineering applicable to offshore installations.

\section{WIND TUNNEL MODELING}

The simulation of atmospheric boundary layer winds constitutes an essential prerequisite to any model study of wind-structure interaction. The similitude requirements may be obtained from dimensional arguments derived from the governing equations for fluid motion. A detailed discussion of similarity requirements and their application to wind tunnel testing is provided by Cermak (1971). In the study of windstructure interactions, strong winds are of primary concern. For these winds, thermal 
stratification of the atmosphere near the surface is destroyed by intense mixing, and the problem becomes one of simulating neutral atmospheric flows which correspond to an isothermal flow in the wind tunnel. The basic requirements for simulating natural winds of this type are:

(1) Undistorted scaling of geometry (geometric similitude),

(2) Reynolds number equality (dynamic similitude),

(3) Rossby number equality (dynamic similitude), and

(4) similarity of mean velocity and turbulence characteristics (kinematic similitude).

A geometric length scale is based on the size of the wind tunnel and various lengths associated with the approach flow characteristics. These lengths are boundary layer height, scale of turbulence and modeling scale for boundary roughness. Under the ideal simulation of a boundary layer, all these lengths should be related to their prototype values by the same linear scaling ratio. This does not always hold exactly true. However, if a boundary layer has been simulated naturally over an approximately scaled terrain. roughness, then the three lengths are generally consistent. Occasionally, a compromise must be reached in length scales to optimize the dimensions of a model to achieve a high quality in model fabrication, instrumentation and transducer application.

For most cases, the exact requirement of equal Reynolds number of model and prototype must be compromised due to the practical difficulties associated with wind speed restrictions and small scales of models involved in wind tunnel experiments. Geometric scale ratios are commonly in the range of 1:500 to 1:100; therefore, unless a compressed air wind tunnel using a fluid such as Freon is used, the laboratory Reynolds number will be smaller than that of the prototype. This relaxation of Reynolds number equality has been found not to be detrimental to modeling since the flow around sharp-edged buildings becomes invariant with respect to the Reynolds number. Relaxation of Reynolds number equality for curve-shaped models, may lead to experimental results that may not represent full-scale behavior. In the following section the mechanics of flow around a circular cylinder and its dependence on Reynolds number is discussed with reference to wind tunnel modeling and possible means of circumventing this limitation.

At low Reynolds numbers, the surface boundary layer on a cylinder is laminar and has a laminar separation at the forward half of the cylinder, generating a wide wake. The corresponding drag coefficient is, therefore, very high. This flow regime is referred to as "subcritical" flow. Most of the low speed boundary layer wind tunnels can attain Reynolds numbers in this regime for scale models exposed to atmospheric boundary layers. For higher Reynolds numbers the transition of the surface boundary layer flow from laminar to turbulent occurs closely after the laminar separation. The separated flow will tend to reattach to the body surface, forming a so-called "laminar separation-turbulent reattachment bubble", and delay the final turbulent separation at about 140 degrees from the stagnation. At this Reynolds number, the wake is narrow and the drag coefficient exhibits a minimum value. It is referred to as critical Reynolds number flow. As the Reynolds number increases the flow transition moves ahead of the separation point and the "bubble" disappears. The turbulent separation point gradually moves downstream and the drag coefficient increases from the minimum as the wake width gradually widens. As the Reynolds number increases further, the flow enters the transcritical region. In this flow regime, the flow transition moves sufficiently 
close to the stagnation. Since the boundary layer on the cylinder surface is turbulent, the fluid particles have greater ability to mix with the outer flow and gain more momentum to overcome the adverse pressure gradient, i.e. cover more ground over the circumference of the cylinder before separating from the body surface at about 110 to 115 degrees from the stagnation line. Most of the full-scale struktural members are well into this regime for typical wind conditions. Furthermore, free stream flow conditions, the end conditions of cylinders and their surface roughness can have marked influence on the flow pattern around a given cylinder (Kareem and Cheng, 1984). The far-field turbulence increases entrainment into the shear layers at the surface of the cylinder and thereby alters the locations of transition, separation and reattachment. The small scale free stream turbulence is known to reduce the Reynolds number at which transcritical flow conditions exist around the cylinder. This appears to be a viable solution for artificially matching Reynolds number between model scale and full-scale. Nevertheless, it poses the problem of gross mismatch Between the length scale of turbulence in the wind tunnel and those in the full-scale conditions. However, one should not ignore the role of small scale turbulence, either present originally in the appropriately simulated turbulent boundary layer, especially near the surface or produced by flow separation and other interactions that may take place, in the modification of flow around curved shaped bodies.

As noted earlier, the major difference between the subcritical and transcritical regions is that the former has laminar separation at the forward face. Therefore, altering the subcritical flow pattern to a transcritical one would either cause the laminar boundary layer transition into turbulent or simply prevent early separation by artificial means. There are two methods which can be employed to cause the transition of laminar boundary layer prior to its separation so that the fluid can gain more momentum to separate at a later stage. The first method is to introduce high intensity, small scale turbulence into the free stream as has been discussed earlier. The other method is to disturb the laminar boundary layer by adding artificial roughness on the curved surface. The artificial roughness can be a uniformly distributed roughness (Achenbach, 1968; Szechenyi, 1975) or discrete two-dimensional roughness strips (Nakamura and Tomonrai, 1982) or roughness elements (Naumann and Quadfleig, 1972); both are influential on the boundary layer transition and subsequent flow development past a cylinder. Kareem and Cheng (1984) used two pairs of trip wires to artificially simulate transcritical flow conditions at low Reynolds number. A pair of wires at $\theta= \pm 65$ degrees from the stagnation line which were referred to as transition wires, were supposed to perturb the laminar flow in the boundary layer and cause transition to turbulent flow. Having gained momentum, the fluid would then be able to travel further downstream until encountering another pair of wires, referred to as separation wires, at $\theta= \pm 115$ degrees. The presence of the separation wires can induce separation at a desired location that matches with that in the transcritical flow regime. To alleviate the two-dimensional wake induced by these pairs of wires, the spanwise continuity was eliminated by stepping wires of shorter length that were alternately staggered along the span (Kareem and Cheng, 1984). No significant difference was observed in the wake induced by this arrangement in relation with the earlier configuration of wires. Therefore continuous wires are recommended in view of their convenience to install. One disadvantage of roughening the cylinder surface is an increase in the drag that results 
from additional roughness and the increase in the effective size of the cylinder. However, this shortcoming accounts for a small percentage increase that is overshadowed by the simulation of high Reynolds number at low Reynolds number flow. In the absence of the above stated Reynolds number similitude the wind tunnel results in some cases may bear little relationship to the corresponding fluid dynamic forces on cylindrical structures in full-scale. The discrete roughness approach was utilized in this study to investigate the influence of altering the flow pattern around cylindrical legs on the overall drag force.

Large wind tunnels cannot be rotated easily; therefore, the requirement of equal Rossby number must be relaxed. Rotation of the earth causes the mean wind to change direction only by about 5 degrees over a height of $300 \mathrm{~m}$ for internal boundary layers developed by strong wind over rough boundaries such as urban areas. Furthermore, the location of a prototype with respect to the latitude has important bearing, e.g. for a zero latitude site there is no change in wind direction.

A turbulent boundary layer simulated by the natural action of the surface shear over a long fetch of surface roughness on the tunnel floor provides good matching of the kinematic similitude requirements. An additional requirement is for the pressure to be essentially constant in the mean-flow direction as it is in the atmosphere. An adjustable ceiling test section can be used to maintain a zero pressure gradient along the test section. Flow simulated by this technique remains in equilibrium in the local surface shear stress. Consequently, the mean velocity profiles and turbulence characteristics are essentially invariant over a significant fetch of the test section. Besides the kinematics of atmospheric boundary layer (ABL), an important characteristic of the turbulent boundary layer is the energy distribution of the wind fluctuations in the frequency domain, i.e. the power spectral density of wind fluctuations. Besides matching the single-point spectral description it is essential to also match multiple-point spectral characteristics, e.g. coherence between laterally and vertically separated locations. An ABL simulated by the natural action of the surface shear over a long fetch of surface roughness will generally have a fluctuating flow field that matches all the statistical features observed in prototype flow conditions for the corresponding fetch roughness.

\section{WIND TUNNEL}

All measurements were made in the Structural Aerodynamics Laboratory at the University of Houston. The tunnel is an open/closed loop type and is approximately $20 \mathrm{~m}$ long and $3 \times 1.75 \mathrm{~m}$ in cross-section. The test section has a movable roof so that satisfactory pressure gradients for all flow conditions can be maintained. An air bearing turntable and remote operation instrument carriage is used for carrying out tests. The turbulent boundary layer is simulated by the natural action of the surface shear over a long fetch of surface roughness on the tunnel floor. The mean speed ranges from 0.5 to $12 \mathrm{~m} \mathrm{sec}^{-1}$ for the full cross-section with higher speeds for the reduced cross-section.

The ocean boundary layer was simulated in the structural aerodynamics boundary layer wind tunnel. A set of spires and a horizontal barrier at the entrance of the test section were used in addition to surface roughness to simulate boundary-layer growth. The data for the wind profile were measured using a Pitot tube connected to an electronic pressure transducer and a hot film anemometer. Both hot film and Pitot data are plotted in Fig. 1 and are in good agreement. The spanwise variations of the wind 


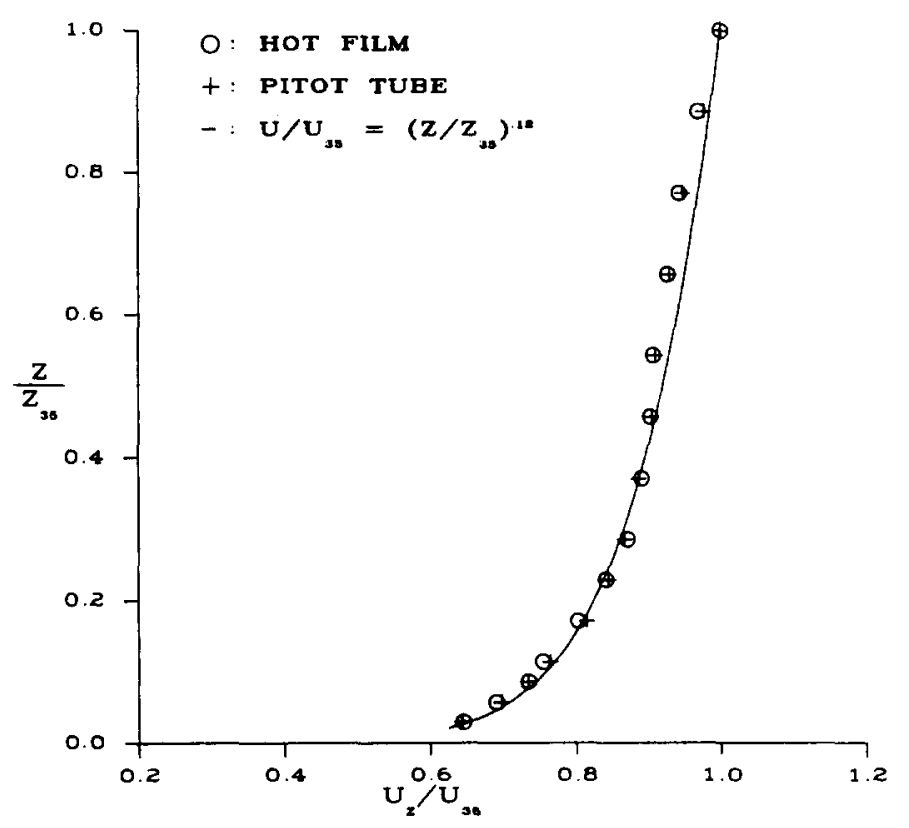

Fig. 1. Mean velocity profile.

field at various levels were measured. The variation in the mean wind field over the middle two-thirds of the test section width was less than $1 \%$.

The constraining or blockage effects of the tunnel walls influence the aerodynamic loads on bluff bodies. The blockage correction depends on the ratio of the projected area of the model normal to the flow over wind tunnel cross-section area. Maskell (1963), developed an approximate relationship between measured and corrected drag coefficients. A detailed description of the wind tunnel blockage effects and corrections are given by Melbourne (1982). The relationship for the blockage correction based on the wind tunnel cross-section and the model area for this study suggested that wall interference effects resulted in an overestimation of drag loads by approximately four percent. The data presented in this report have not been adjusted for blockage.

\section{TLP MODEL}

The scale of the model was 1:128 and was derived on the basis of the area of the tunnel cross-section, and model details, etc. Only the portion of the TLP above the mean water level was built. The model was constructed out of plastic, brass, and aluminum to avoid unnecessary movements of components during the tests which could lead to cracks (Fig. 2).

Major components on the upper deck, such as those identified below, were designed for easy removal to enable testing to be conducted in their absence. However, these components were rigidly attached to the model during the test:

(i) drilling derricks and substructures that can be repositioned to represent their range of service to 20 well slots each, 
(ii) living quarters,

(iii) helideck,

(iv) cranes and crane pedestals,

(v) flare boom,

(vi) utility decks,

(vii) pipe rack, and major components and equipment underneath it.

A simple representation of the lower and mezzanine decks was used by employing a mesh with about $50 \%$ porosity, rather than the detailed arrangement of equipment present. The moon pool and the fire walls around the moon pool in the lower and mezzanine decks were included in the model. Figure 2 shows the model with all the ancillary structures on it. This is referred to as base case in this report.

All the components of the superstructure, with the exception of a few small components and the four legs, had sharp corners. As stated earlier, for these components with sharp edges that provide well defined separation, the departure from Reynolds number similitude does not affect the force measurements. However, it is essential to ensure that lack of Reynolds number similarity is taken into consideration. In conventional wind tunnels it is not possible to reach full-scale Reynolds number for scaled models of structures. Therefore, alternative means of simulating high Reynolds number flow around members of circular cross-section are considered. The application of homogeneous and/or discrete roughness on the surface of a member of circular crosssection helps to modify the flow characteristics around the cylinder such that it can represent full-scale conditions. Alternatively, the model dimensions may be scaled according to the ratio $\left(C_{\mathrm{D}}\right)$ model $/\left(C_{\mathrm{D}}\right)$ prototype. In this manner the overall drag force measured in the tunnel can be faithfully transformed to the full-scale values. The key factor in this approach is the ratio of the drag coefficient corresponding to the model and the prototype Reynolds numbers. There may be some uncertainty associated within this ratio. This uncertainty may especially increase for situations where interference effects are predominant and the cylinders have low aspect ratio and are exposed to turbulent shear flow.

In this model the above water portion of the circular legs is a special case of circular cylinders which have very low aspect ratio and have two levels of platform deck on the top. The legs in the rear experience complicated intereference effects. These cylinders are exposed to the lower portion of the boundary layer with maximum velocity gradient and turbulence intensity. In view of the above mentioned conditions, obtaining a reliable estimate of the scaling ratio for the stubby cylinders was unlikely. Furthermore, the projected area of the cylinders is a small percentage of the overall platform area and their location is in the region of lower velocity with respect to the rest of the platform. Therefore any overestimation of drag on these cylinders will not contribute significantly to the overall force and moment measurements. Nevertheless, in this study as indicated earlier the cylinder surface was augmented with discrete surface roughness to observe the effectiveness of an artificially induced high Reynolds number flow field on this structural configuration. The influence of this roughness on the force and moment measurements is discussed in a later section.

\section{TEST CONFIGURATIONS}

A number of model configurations were tested by modifying or removing component of the basic platform model. These configurations are 
(1) Base case study (Fig. 2), one drilling derrick in northwest location and other in southeast.

(2) Base case study (Fig. 3), same as (1) except move northwest derrick to northeast.

(3) Base case as in (2) with northeast derrick removed (Fig. 4).

(4) Base case with both derricks removed (Fig. 5).

(5) Same as in (4) with cranes and pipe storage removed (Fig. 6).

(6) Base case with everything removed except flare boom, helideck and living quarters (Fig. 7).

(7) Same as in (6) with living quarters and helideck removed (Fig. 8).

(8) Base case with everything removed from the platform (Fig. 9).

In addition to the above configurations, test runs were made by covering one side of the derrick to represent a wall of pipes normally placed during drilling operation. Test runs were also made at different wind speeds and by installing discrete surface roughness to simulate an artificially high Reynolds number flow field around the TLP model legs.

\section{Force transducer and instrumentation}

A special six-component force balance was designed and built for this study. Due to the large size of the model the force balance was required to be sturdy as well as sensitive to small changes in loads. These characteristics were taken into consideration. Strain gages were used in a number of configurations to measure six force and moment components. The strain gages were installed with precision to minimize cross-talk and other spurious interactions. The output of the six-channel transducer was sent through a signal conditioning unit and amplifiers before being fed into the analog-to-digital converter. The analog-to-digital converter was interfaced with a PDP Micro-11 computer for data acquisition and reduction (Kareem $e t$ al., 1985).

The wind velocity during a test run was continuously monitored using a Pitot tube located at 28 in. from the tunnel floor. The Pitot tube was connected to an electronic pressure transducer and the signal after amplification was fed into the data acquisition system.

The force balance requires calibration to establish a relationship between the input loads and the output voltages. A special calibration jig was designed to apply loads in various directions and a computer-aided calibration procedure was developed. For each calibration loading direction a range of loads were applied to establish the linearity of the transducer (Kareem and $\mathrm{Lu}, 1985$ ).

\section{FORCE AND MOMENT MEASUREMENTS}

The tests for the force and moment measurements were conducted over azimuth angles of 0 degrees to 360 degrees at 15 -degree intervals. Additional measurements were made at 22.5 degrees azimuth angle. For each direction, three sets of 60 -second data were taken at a sampling rate of 200 samples/sec. These three segments were further averaged to give $180 \mathrm{sec}$ mean force and moment measurements.

The data was measured and reduced to obtain mean values of forces and moments using the calibration matrix described earlier. The measured body axis forces and moments were expressed in terms of non-dimensional body axis force and moment coefficients. These coefficients are 


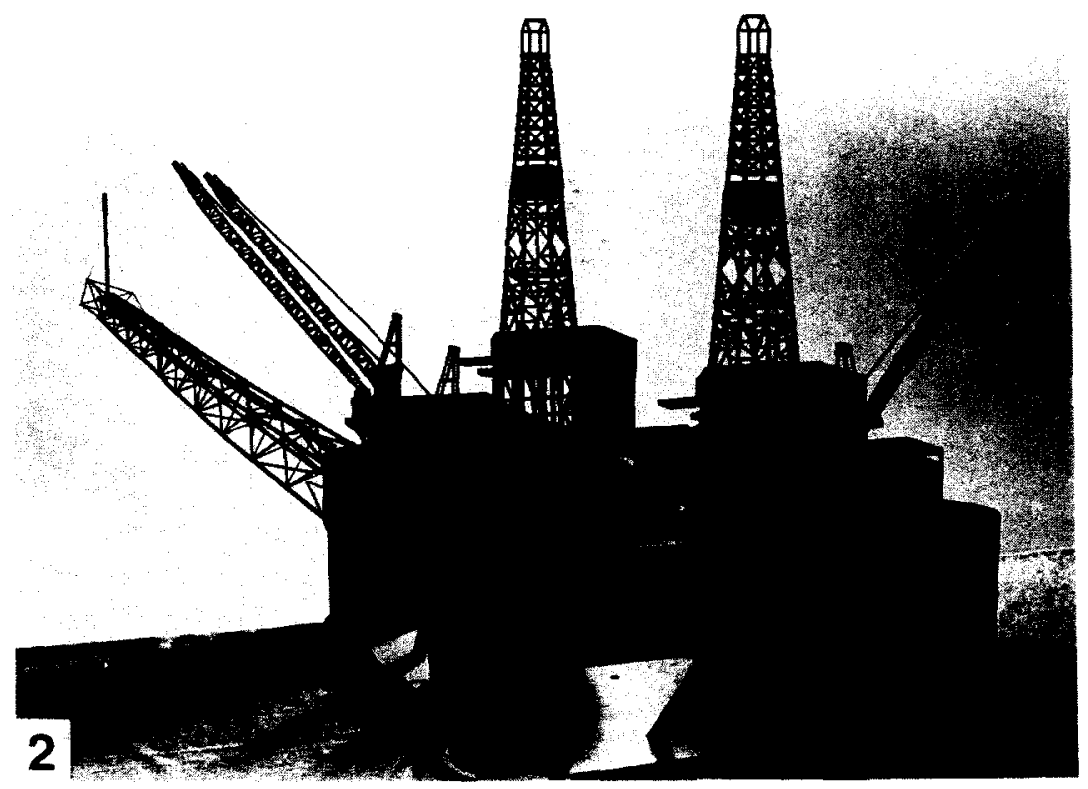

FIG. 2. TLP model configuration 1.

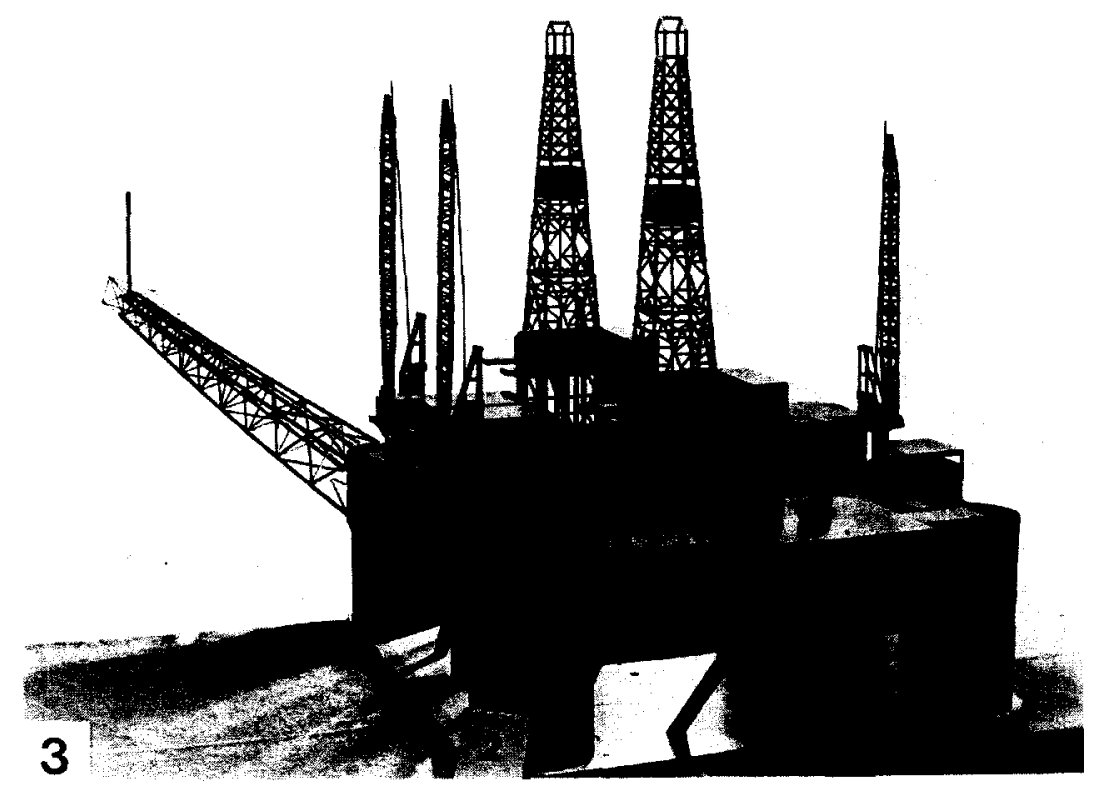

Fig. 3. TLP model configuration 2. 


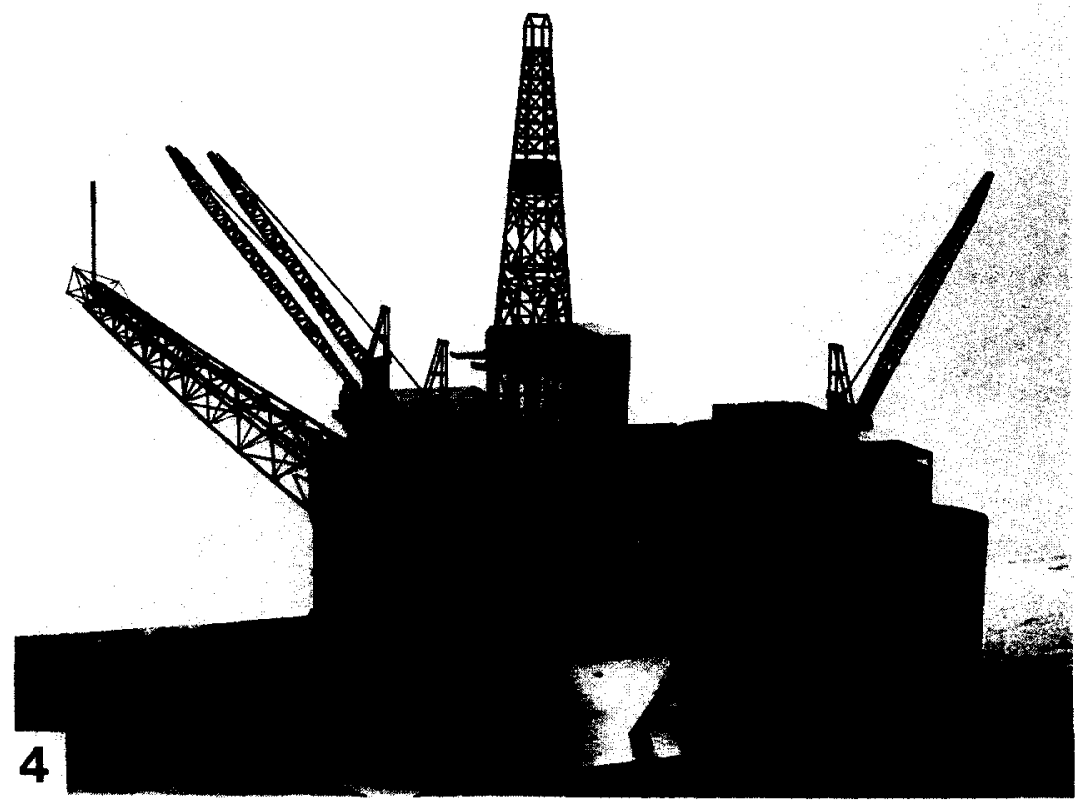

FIG. 4. TLP model configuration 3.

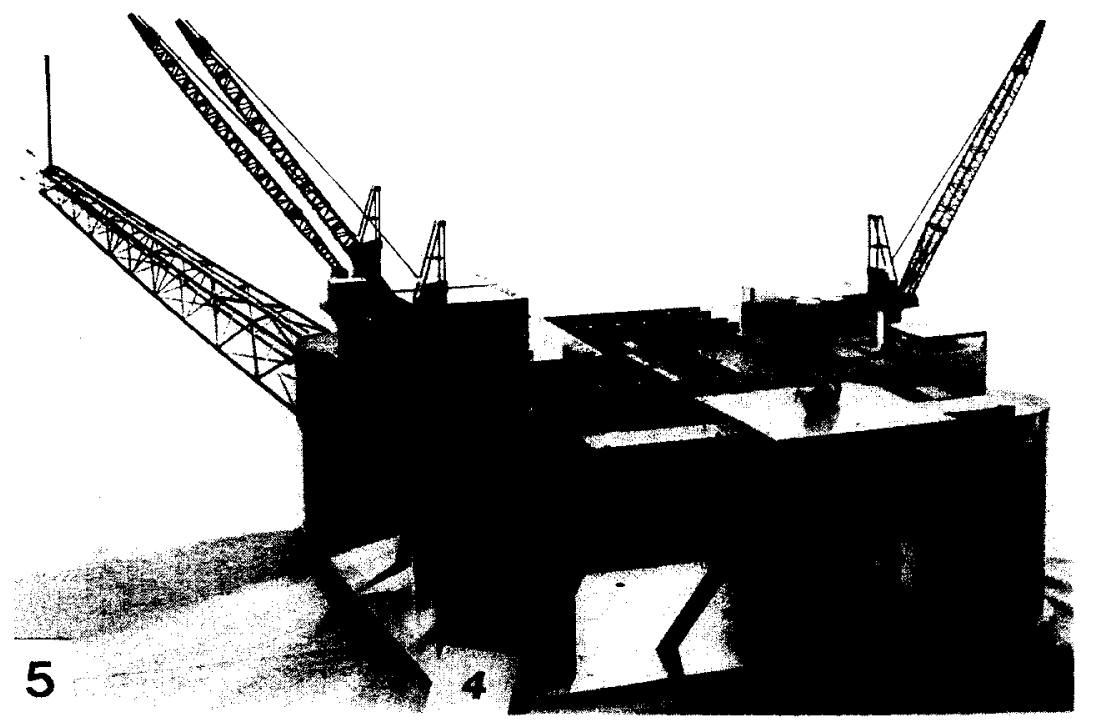

FIG. 5. TLP model configuration 4. 


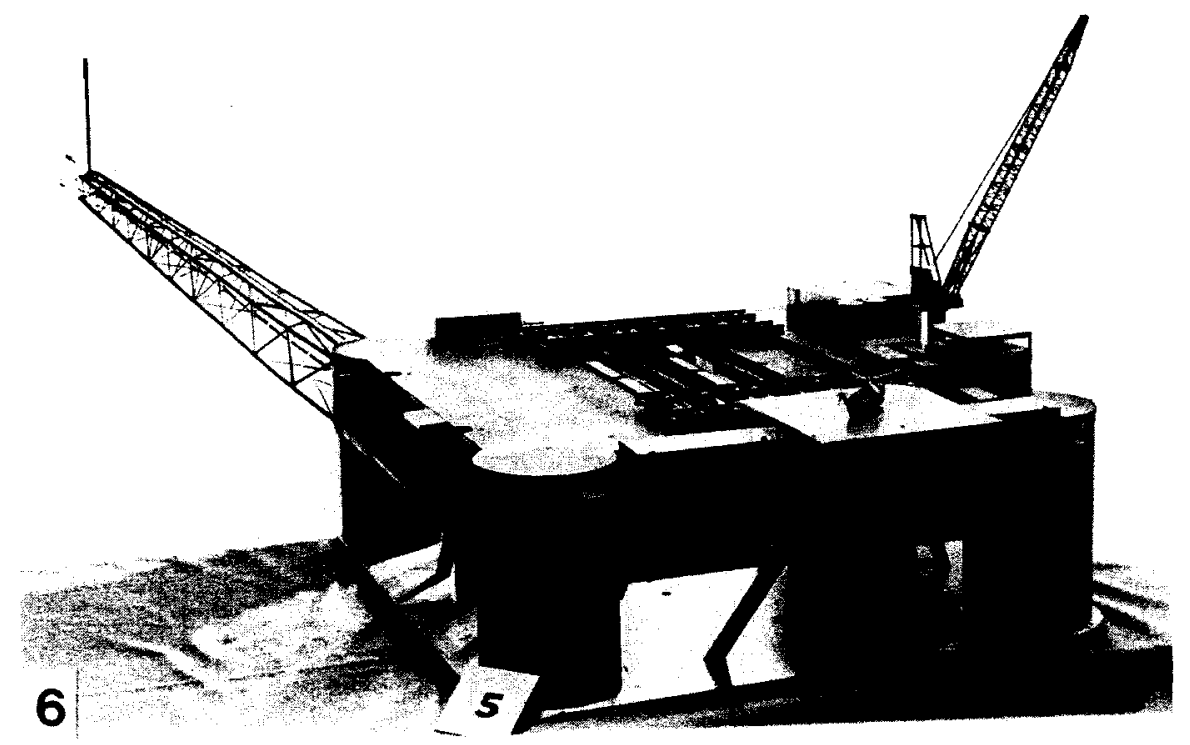

Fig. 6. TLP model configuration 5.

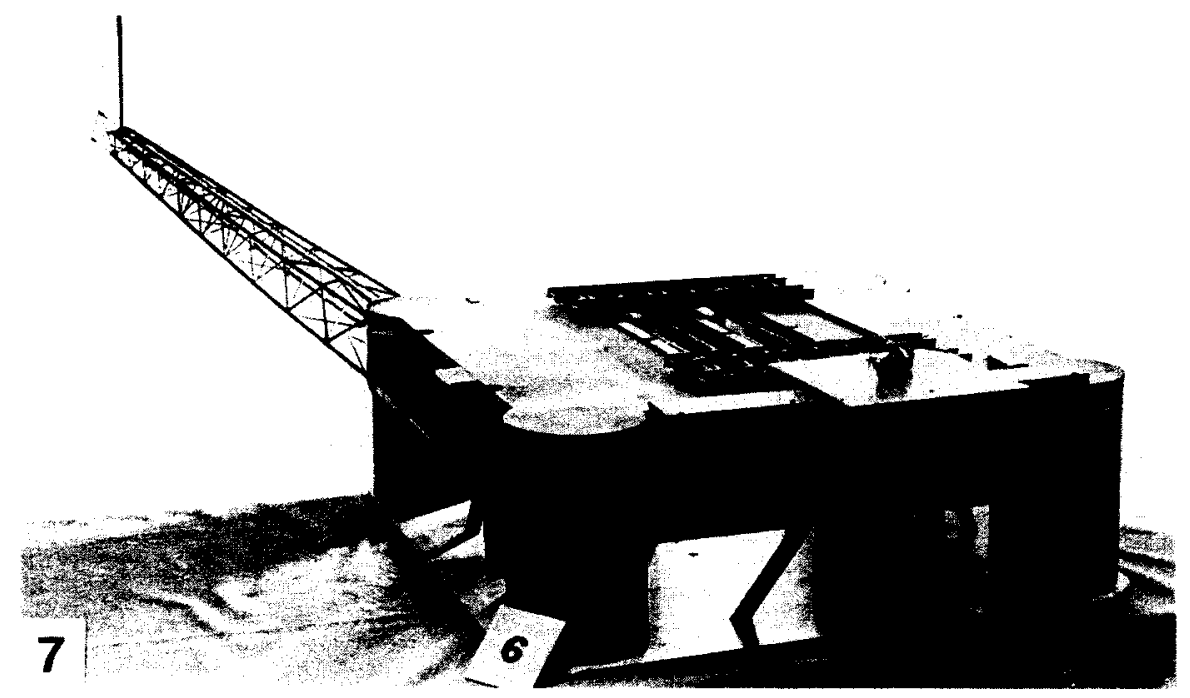

Fig. 7. TLP model configuration 6. 


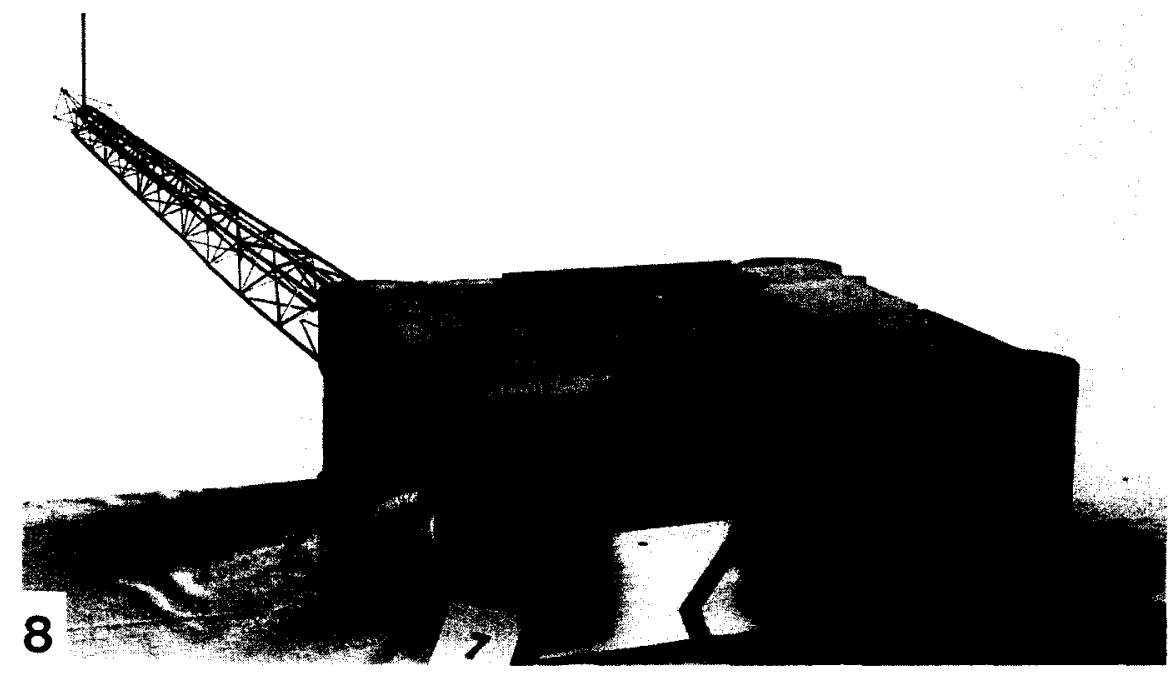

Fig. 8. TLP model configuration 7.

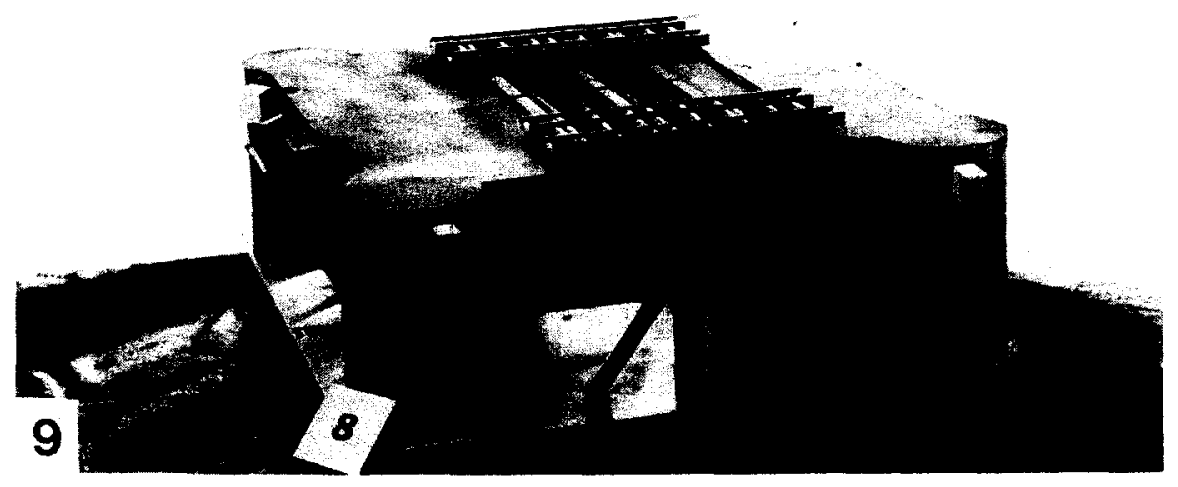

FIG. 9. TLP model configuration 8. 


$$
\begin{array}{rlr}
C_{F_{i}} & =\frac{F_{i}}{\frac{1}{2} \rho U^{2}\left(z_{\mathrm{ref}}\right) A_{\mathrm{ref}}} & i=1,2, \text { and } 3 \\
C_{M_{i}}=\frac{M_{i}}{\frac{1}{2} \rho U^{2}\left(z_{\mathrm{ref}}\right) A_{\mathrm{ref}} L_{\mathrm{ref}}} & i=1,2, \text { and } 3
\end{array}
$$

in which $F_{i}$ and $M_{i}=$ measured forces and moments with respect to the body axis (Fig. 10), $\rho=$ air density during the experiment, $U=$ mean wind speed at reference height, $A_{\text {ref }}=$ reference area and $L_{\text {ref }}=$ lever arm, and $C_{F_{i}}$ and $C_{M_{i}}=$ force moment coefficients with respect to the body axis. In this study both $A_{\text {ref }}$ and $L_{\text {ref }}$ were chosen to be unity
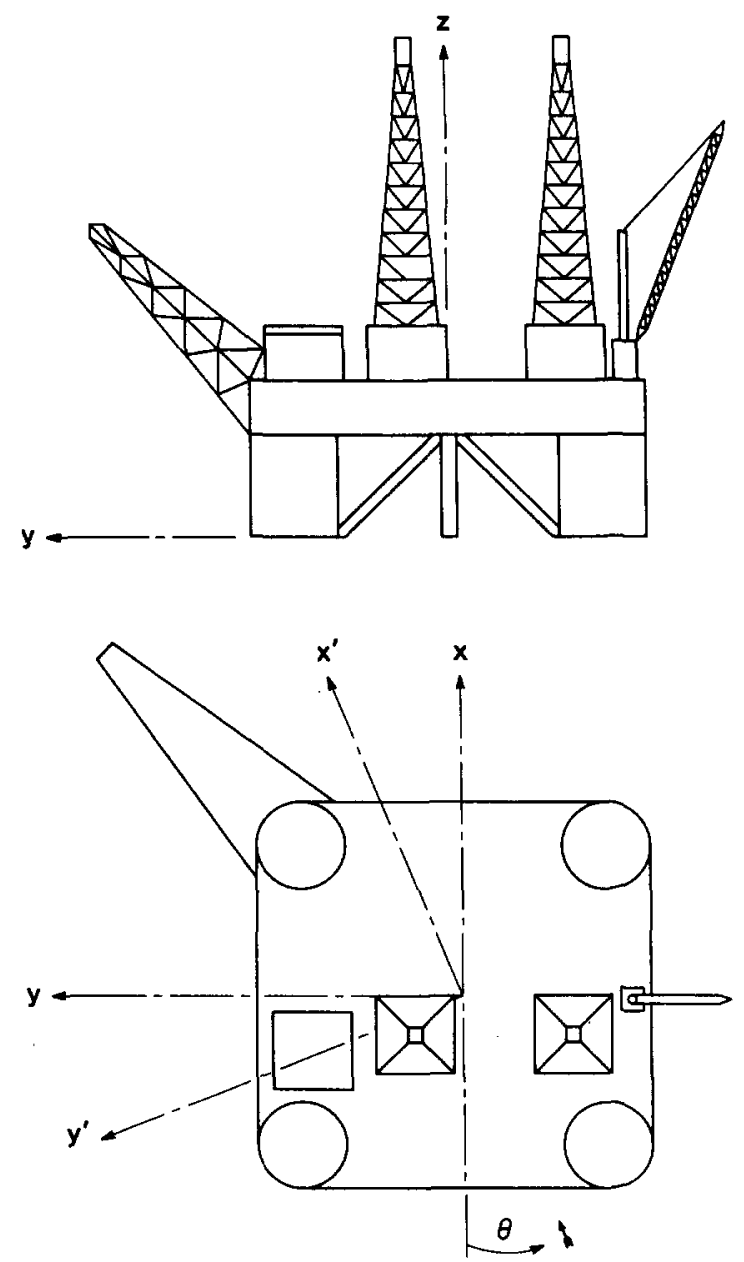

FIG. 10. Coordinate system. 


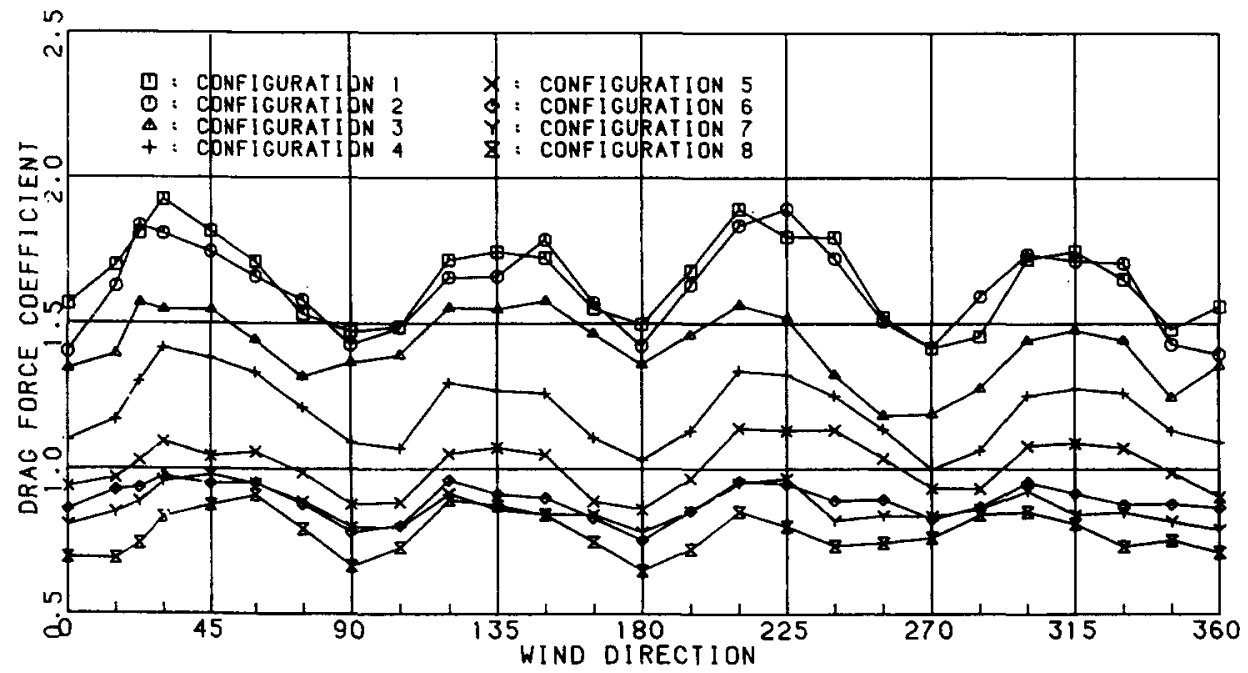

Fig. 11. Drag force coefficients-Tested model configurations.

for convenience in data reduction and subsequent evaluation of the full-scale values. This selection of the reference area and lever arm alleviates any error in the measurement of projected area and lever arm for different azimuth angles that may be introduced in the force and moment coefficients. The force and moment coefficients may easily be modified to include the actual frontal areas and lever arms for any desired configuration.

The body axis forces and moment were transformed to the wind axes. These force and moment coefficients are more commonly used, e.g. drag, transverse, and lift forces and moments associated with these forces. This transformation is accomplished through a direction cosine matrix derived from Fig. 10 (Kareem and Lu, 1985).

The moments are measured with respect to a distance of $1 / 4$ inch below the mean water level ( $2.66 \mathrm{ft}$ full-scale). These moments may be conveniently transformed to any other reference level.

\section{RESULTS AND DISCUSSION}

The aerodynamic force and moment coefficients for the tested configurations are plotted as functions of the approach wind direction in Figs 11-16 (Kareem and Lu, 1985). In Fig. 11 the drag coefficients have maximum values for both base cases (configurations 1 and 2) and minimum values for the platform with all the ancillary structures removed (configuration 8). The plotted values exhibit a trend of successive valleys and peaks with maximum values for the wind directions along the diagonals and minimum values for wind direction perpendicular to one of the sides. This trend can be attributed to the fact that the drag coefficients for all wind directions were obtained by normalizing with the same reference area. However, the frontal area changes with the wind direction, leading to maximas for wind approaching along diagonals that contributes maximum projected area with maximum associated aerodynamic force. The difference in the values of the drag coefficient for the two base case studies indicates that interference and proximity effects do influence the aerodynamic force. For wind 


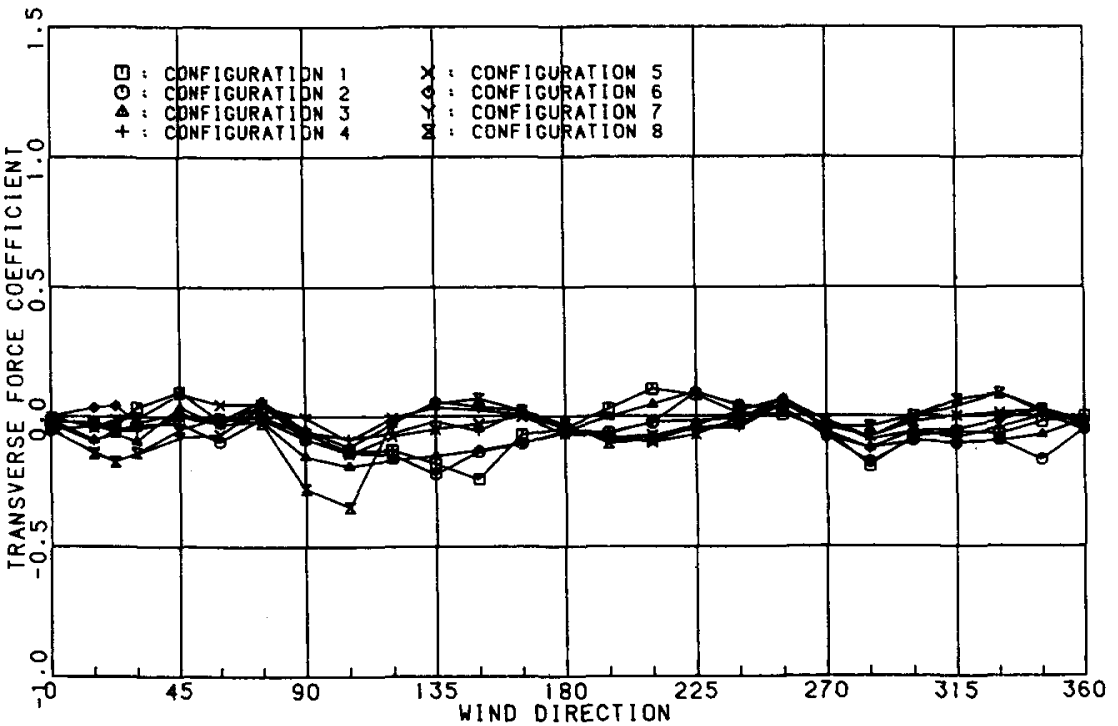

FIG. 12. Transverse force coefficients-Tested model configurations.

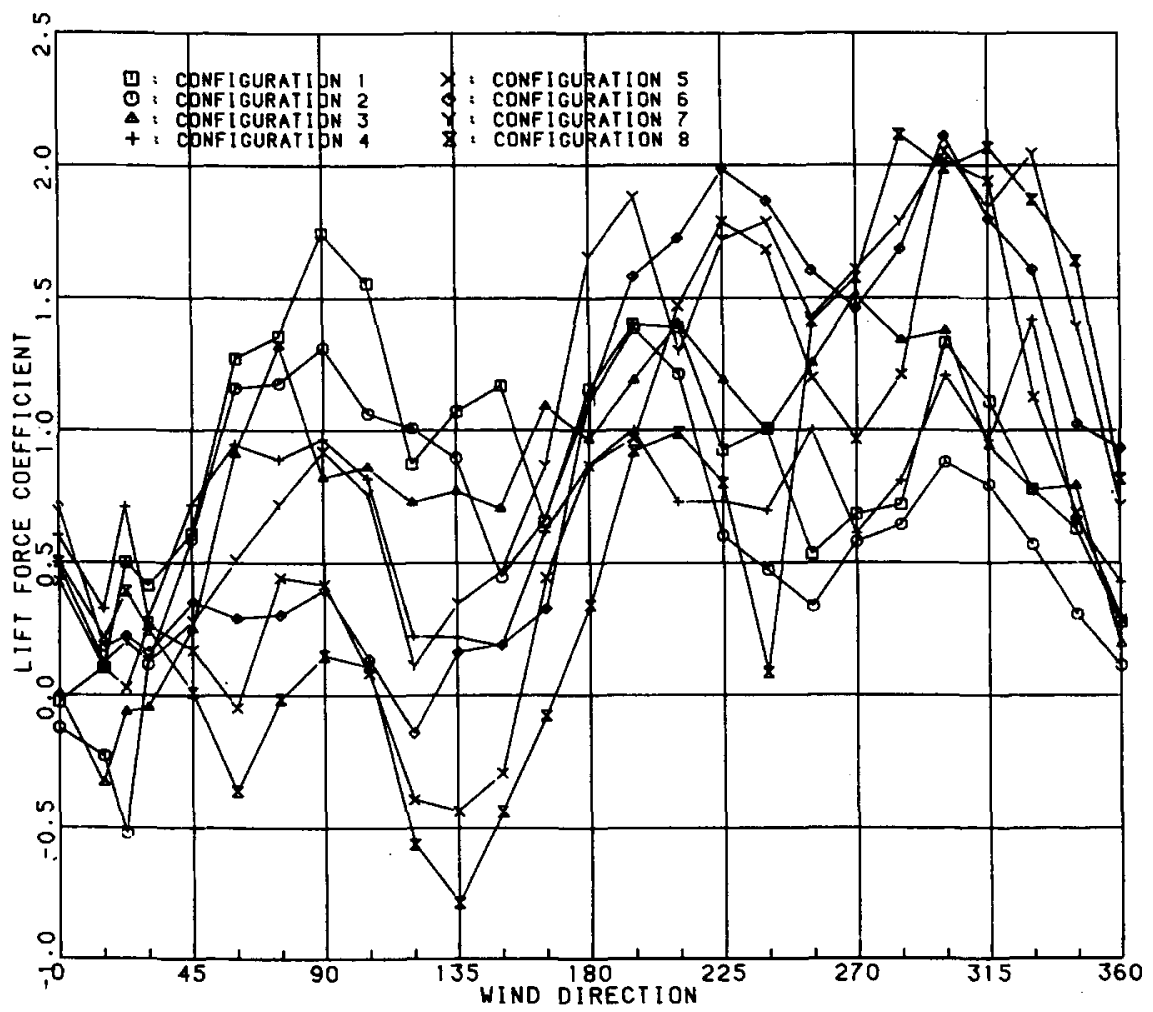

Fig. 13. Lift force coefficients-Tested model configurations. 


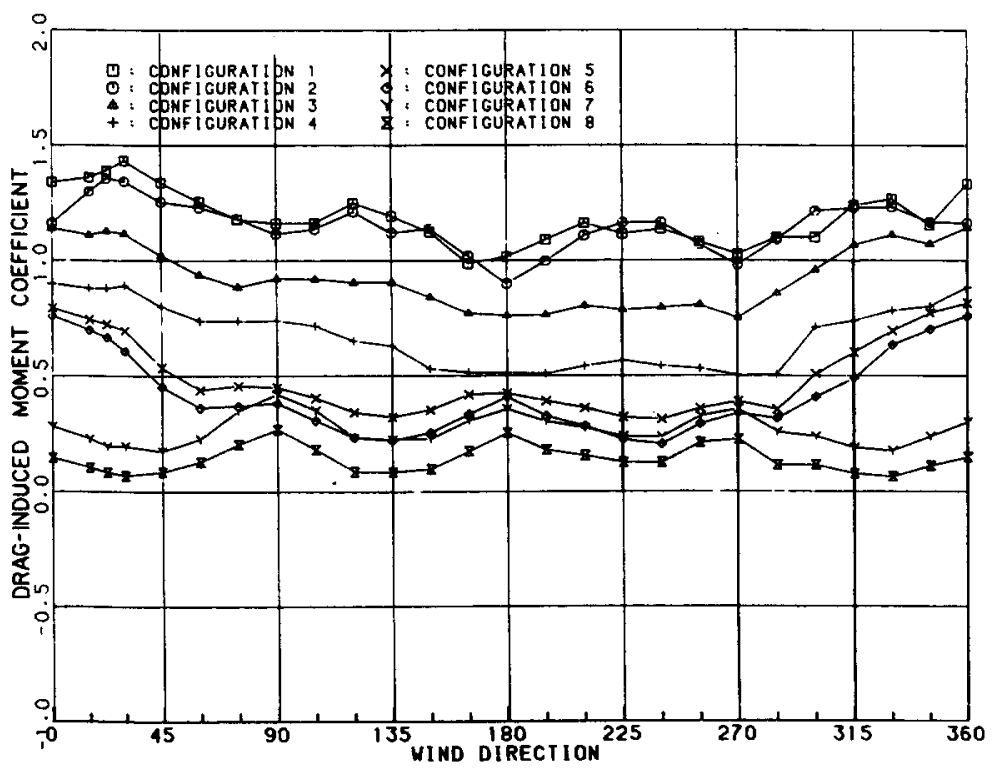

FIG. 14. Drag-induced moment coefficients-Tested model configurations.

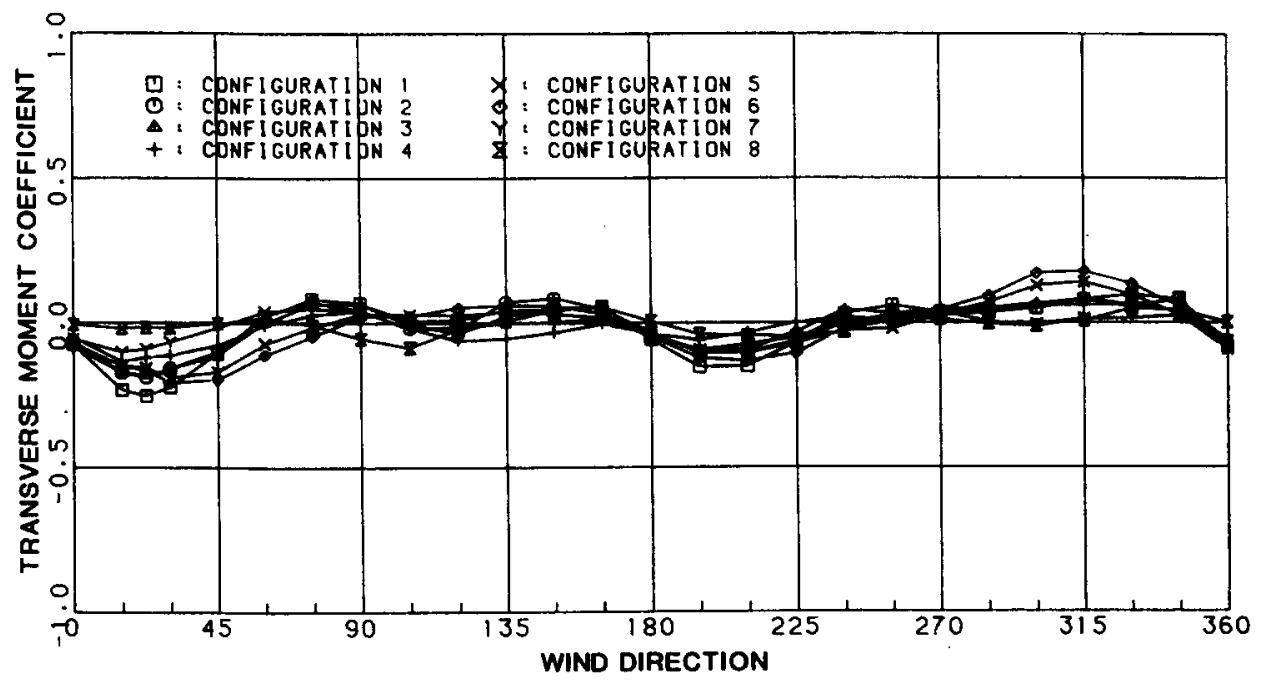

Fig. 15. Transverse moment coefficients-Tested model configurations.

approaching at zero degree angle of attack, the base case corresponding to configuration 1 had a higher drag coefficient in relation to configuration 2. Although both configurations are comprised of the same ancillary deck structures with the same configuration except for the location of two drilling derricks (Fig. 2), in configuration 


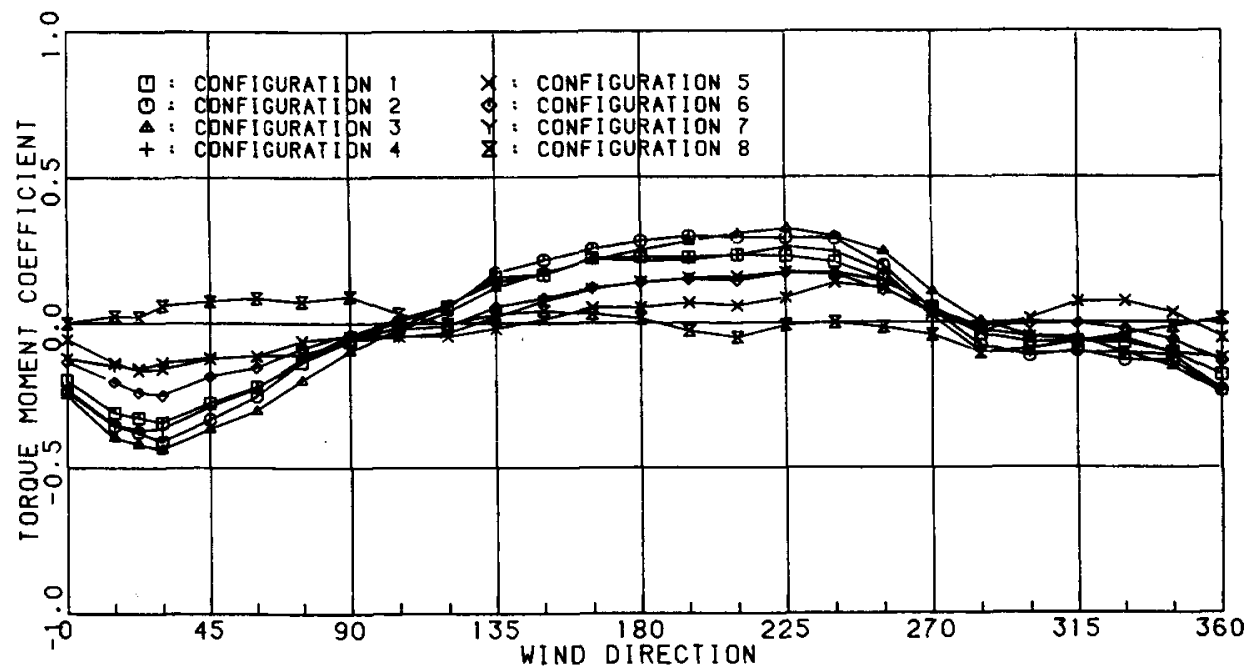

Fig. 16. Torsional moment coefficients-Tested model configurations.

1 both derricks were exposed to wind for zero angle of attack, whereas in configuration 2 the south side derrick was located in the shadow of the front derrick which resulted in an overall reduction in the drag as exhibited in Fig. 11. The removal of one derrick in configuration 3 resulted in a significant reduction in the drag. In configuration 4, both derricks were removed and the drag values showed a further reduction, e.g. the drag coefficient dropped from 1.57 , for the base case, to 1.1 for both derricks removed. This trend suggests that the two derricks have a significant influence on the overall drag of the platform for all the tested wind directions. There is a concomitant decrease in the drag coefficient as the deck structures are removed corresponding to configurations 5, 6, 7 and 8 leading to a basic platform superstructure without ancillary components.

For various wind directions the downstream columns are shielded by the upstream cylindrical legs, a situation which may result in a reduction in the drag force. The force estimates based on a projected area approach may tend to overestimate the force if the effects of the column shielding are not adequately included in the calculations. The ABS guidelines do not suggest any compensation for column shielding. However, the $\mathrm{DnV}$ specifications do suggest a reduction in the contribution to drag due to the shielding effect. Such effects are quantified based on wind tunnel tests employing twodimensional cylinders at low to moderate turbulence level. However, these effects are not well understood in the case of stubby cylinders of low aspect ratios with end plates in highly turbulent shear flows. In the case of a TLP the end conditions are often represented at one end by the sea surface, whereas the other end is abutted on to a double-level platform deck. It seems unlikely that for this platform configuration the drag contribution is notably reduced by the upstream legs. Despite the fact that the end conditions reported for the legs point towards a possible two-dimensional flow pattern, it is not known whether under the present flow conditions, which exhibit 
marked three-dimensionality and small spatial coherence, such an idealization would faithfully represent the flow pattern. This brings out another question regarding the choice of the drag coefficient for this situation. By examining the drag for configuration 8 , assuming that the wind tunnel simulation was independent of Reynolds number, all three approaches provided close estimates. It appears that for the TLP example in hand, with very short and stubby columns, any corrections for the shielding and the aspect ratio effects is compensated for by the ABS guidelines that recommend initially a lower drag coefficient without any compensation for these effects. The drag coefficient was a maximum for the base case (configuration 1) with the wind approaching at 30 degrees from the north.

In Fig. 12, the transverse force coefficient, i.e. perpendicular to the mean wind direction, showed no significant variation with a change in the mean wind direction except for configuration 8 at an angle of 105 degrees.

The variations in the lift force with the change in the approach angle exhibit more significant changes and are sensitive to different configurations (Fig. 13). The quality of data in the lift direction was not as good as the other force and moment components due to the relatively low sensitivity of the force balance in this direction. Secondly, the two levels of the deck in the model present aerodynamic surfaces about which the flow tends to separate and reattach on either side. This situation lent itself to the development of unsteady flow induced lift forces in which the fluctuating components were significant in relation to the mean values. It is expected that some uncertainty in the lift force data was introduced by this phenomenon. The actual magnitude of the lift forces is unlikely to be of any significance in the design of a TLP due to their magnitude in comparison with the wave induced loads and the structural mass of the platform. Nevertheless, the contribution of the lift forces to the drag-induced overturning moment is noteworthy. This load effect was adequately measured by one of the most sensitive components of the force balance system used in this study.

The drag-induced overturning moment or pitching moment is plotted as a function of wind direction in Fig. 14 and generally follows the variation of the drag force with the wind approach angle. The measured pitching moment includes contributions from both direct aerodynamic sources, e.g. moment induced by the drag force, as well as the flow-induced effects, such as lift forces resulting from flow separation. The flow separation takes place at the leading edge of the deck and is more predominant at the living quarters and the helideck. In the absence of a leading edge for separation the lift induced is less effective due to several deck components obstructing the flow. The unsymmetrical distribution of lift induced at the leading edge surface tends to enhance the overturning moment. It is flow-induced load effects such as the lift-induced pitching moment which cannot be estimated using code specifications and often are neglected in the design procedure. These effects may be seen by examining the values of the drag-induced moment at wind approach angles of 0 and 180 degrees. The projected area procedure based on code specifications would suggest little or no difference between the moment coefficients for the aforementioned azimuths. However, there is a reduction in the value of the moment coefficient when the wind approaches from 180 degrees in relation to the zero azimuth value. This difference can be attributed to the lift-induced moment contribution from the helideck and the living quarters that are located near the leading edge of the structure for wind approach angle of zero degrees. 
Additionally, separated flow not only induces vertical lift but, in the event of no reattachment, exposes some structural components to high velocity regions due to accelerated flows. A combination of these flow-induced effects causes changes in the measured values of the pitching moment. The drag-induced moment is also notably influenced by the contribution from the loads on the drilling derricks. Also, there is a marked decrease in the moment coefficient when the test configuration is changed from 6 to 7 . Aerodynamically, the physical removal of the helideck and the living quarters eliminates the lifting surface provided by these deck structures, thereby reducing the overall moment coefficient at a wind approach angle of zero degrees. This effect is not that substantial for a wind approach azimuth of 180 degrees, in this case the presence of the lifting surface on the downwind side of the platform makes little difference aerodynamically in relation to the overall moment. The drag-induced moment on the base case model configuration was greatest, like the drag force, for the wind approaching at 30 degrees.

The transverse force induced moment or the roll moment does not exhibit any significant variation with the wind azimuth (Fig. 15). These moments are induced as a result of lack of symmetry in the geometry of the deck structures with respect to the mean wind field. Some contribution may result aerodynamically from a deflected high velocity region in the acrosswind direction. However, such a contribution is little, if any, and primarily it is of the fluctuating type.

The torsional or yaw moment that result from an imbalance in loading on structures resulting from asymmetrical structural geometry or a spatial variation in the approach wind field are given in Fig. 16. The torque moment coefficients are slightly sensitive to the changes in wind azimuth, especially for configurations 1,2 and 3 . These coefficients have very small values for configurations with a lesser number of deck components. Torsional loads induced by the wake effects appear to be less prominent for a TLP structure that generally lacks a coherent wake.

Additional measurements were made to investigate the dependence of measured force and moment coefficients on Reynolds number corresponding to a range of wind speeds. This was accomplished by repeating measurements for different azimuth angles at wind speeds ranging from 14 to $29 \mathrm{ft} / \mathrm{sec}$. The measurements showed very small variations of the force and moment coefficients with changes in the wind speed. In , quantitative terms the variation of a typical coefficient was less than a few percent for the range of test speeds investigated. An additional series of tests was conducted at artificially induced high Reynolds number flow around the legs of the TLP by employing discrete roughness elements at selected locations on the circumference of each leg. Measurements were performed at the range of wind speeds discussed earlier to observe the influence of surface roughness on the measurement of the force and moment coefficients. Two discrete roughness configurations were tested:

(a) a set of transition wires of 0.03 in. dia. at \pm 65 degrees from the stagnation line and a pair of separation wires of $3 / 32$ in. dia. at \pm 115 degrees;

(b) a pair of only separation wires of 0.125 in. dia. at \pm 45 degrees from the separation line.

No significant influence of such roughness elements was observed in this investigation. These results suggest that the stubby legs of the TLP with low aspect ratios, exposed to a three-dimensional flow field characterized by a very high level of turbulence and 
strong shear may have rendered apparently successful technique, of utilizing surface roughness on isolated cylinders to simulate high Reynolds number flow, inapplicable to the cylindrical columns of the TLP model. On the other hand, the cylindrical legs in a flow field characterized by intense turbulence level and vortical structures that initiate from the TLP deck may become relatively insensitive to the Reynolds number. Furthermore, the insensitivity of measured value in the presence of added roughness may also be attributed to the relatively low contribution of the cylindrical legs to the overall drag as a consequence of small frontal area near the mean sea surface that is exposed to the lower wind speeds.

The downwind side of the derricks was masked to simulate the blockage effect of pipes stacked against the side. This configuration was studied for $0,22.5$ and 45 degrees only. An additional configuration was tested for the same angles in which the cover was extended down to the derrick substructure. In both of these test configurations the aerodynamic loads have increased slightly with a maximum value at 22.5 degrees for the derricks covered only.

The overall accuracy of experimental measurements can ideally be obtained by considering each component of the measurement system. However, there are a number of additional factors influencing the level of accuracy. It is very difficult to estimate the level of any bias errors in the consideration of experimental procedures. Therefore, repeatability of each measurement, though not a measure of the absolute accuracy of each measurement, has been considered as an assessment criterion for consistency. This seems to be a more realistic and easily understood measure of the quality of measurements. The calibration of the force transducer and velocity measurement system was checked three times during this investigation. The overall repeatability was within $5 \%$ for the measured force and moment coefficients.

\section{FLOW VISUALIZATION}

As the wind encounters an offshore platform such as a TLP it exerts pressure on the windward face of the platform and the deck structures. The wind is then deflected around bluff deck structures and accelerated such that the velocity passing the upwind corners is greater than the velocity approaching the structure. The high-velocity fluid cannot turn the sharp corners and thus separates from the structure, leaving a region of high negative pressure. In case of open lattice-type structures some of the fluid goes through the structure and the rest interacts with the structural components and undergoes separation.

A typical platform exposed to turbulent atmospheric boundary layer flows, experiences complex fluid-structure interactions in which the turbulent flow field suffers distortion and the resulting flow field around the platform becomes extremely complex. This complex field is further complicated by aerodynamic interference and associated interactions. These interference effects result in either adverse or beneficial aerodynamic loading that can be identified as changes in the local pressure or in the overall aerodynamic loading. These effects have been to some extent quantified in the previous sections dealing with wind tunnel measurements. In addition to the load effects the flow patterns and their severity can significantly hamper the serviceability and operational efficiency of the platform by inducing high levels of turbulent flows. To name a few, the adverse wind conditions may impose severe environmental problems for helicopter 
landing and take off, drilling operation and safety of personnel. These adverse flow conditions can be identified using a flow sensor around the platform model in a simulated flow condition using a boundary layer wind tunnel. Such a quantitative mapping of the flow becomes quite expensive, therefore alternative means that utilize qualitative estimates such as flow visualization experiments become very attractive. Direct observations of the visualized flow as well as photographic records using various flow visualization techniques, contribute significantly to the understanding of the mechanisms involved in complex flows. For many flow fields in air, optically dense smoke-filament lines are often introduced into the flow field. The smoke may be generated by burning a coating of paraffin from a nichrome wire. A vertically-oriented "smoke wire" may be used to introduce controlled sheets of smoke streaklines. A regulated supply of oil drops from a small reservoir is allowed to fall, coating the wire along its length. The oil film is burned off subsequently through the resistive heating of the wire that generates a discrete streakline of smoke. A synchronized circuit may be added for triggering the smoke, strobe lights and a camera for taking photographs (Corke et al., 1977).

The smoke generated by such a system developed for this study was introduced in front of the model from various directions and a video-tape recording as well as still photographs were taken. Figure 17 is a still photograph of the flow around the northern face of the platform and emphasizes the separated flow over the helideck. The flow also separates at the leading edge of the bottom of the lower deck and may result in a lift force in the opposite direction. In Fig. 18 flow around one of the cylindrical legs for wind approaching at 45 degrees is shown. The flow separates over the flat top of the cylinder, whereas there are two different patterns for the flow around the cylinder. The portion of the cylindrical leg between the two decks has large ribs attached at the stagnation line and at 90 degrees from the north that induce separation at 90 degrees. The lower portion of the cylinder does not have any protuberance, therefore the visualized flow appears to be wrapped around the cylinder up to the point where natural separation occurs. This study suggests that the presence of sharp edges and corners would induce turbulence that may influence the working conditions on the deck. The geometry of the helideck is introducing an additional flow-induced moment as well as adverse conditions for helicopter landing. Modifications that facilitate the separated flow management around the deck would help to alleviate both predicaments.

\section{COMPARISON OF METHODS}

The experimentally-derived force and moment coefficients were used to validate the estimated values of these coefficients based on the projected area approach. The synthesis of the overall force and moment coefficients was carried out in accordance with the procedures recommended by ABS and DnV, although other societies have quite similar guidelines.

The procedures recommended by the ABS and $\mathrm{DnV}$ require that the frontal area of a platform be divided into various surface components. Each component is assigned a force coefficient based on its geometry utilizing a data base of drag coefficients for a host of simple traditional shapes. Generally, these drag coefficients are based on wind tunnel experiments involving basic structural shapes that are tested in the absence of any adjacent structural component. The drag force acting on each component is given 
by $F_{\mathrm{D}}=1 / 2 \rho C_{\mathrm{D}} A_{\mathrm{p}} U^{2}$, in which $\rho=$ air density, $C_{\mathrm{D}}=$ component drag coefficient, $A_{\mathrm{p}}=$ projected area, $U=$ mean wind velocity. The sum of the component drag forces is equal to the total drag force on the platform. The location of the resultant drag force is obtained from the component-force weighted centroid. Following a similar approach the associated drag-induced moment may be computed as a product of the resultant drag force and the distance between the point of action on the resultant force and the level at which the moment is desired. Similarly, torsional or yaw moments can be obtained. The procedure outlined above appears to be relatively simple and provides a convenient, flexible and practical design tool for tailoring the design of offshore platforms. Nevertheless, the use of a projected area approach is thought to be conservative. Hence, this approach is useful only for the preliminary design of structures where it provides flexibility to incorporate numerous platform configurations at minimum cost in comparison with a full-blown wind tunnel test. However, since wind load effects on TLPs are recognized to be a significant environmental loading, a design based on wind tunnel tests is believed to be always cost effective.

There are some differences between the DnV and ABS recommended procedures. The $\mathrm{DnV}$ guideline requires relatively higher values of drag coefficients for traditional structural shapes than comparable ABS values. However, DnV suggests including provisions for drag reduction due to the shielding effect of adjacent components located parallel or normal to the wind direction and/or located behind each other. Furthermore, the DnV specifications address the modifications introduced by configurations, such as stubby individual members with low aspect ratios and three-dimensionality in the flow field around a structural component. There is no comparable provision for shielding effects in the ABS specifications. Additionally, the DnV specifications recommend a continuous velocity profile, represented by a power law exponent, whereas the ABS guidelines suggest a staircase idealization of the wind speed variation with height above the mean water surface. The two prominent differences in the treatment of both drag coefficients and the variation in the wind speed with height may generally lead to some differences in their respective drag coefficients for the overall structure. However, in this study a power law variation in the wind speed with height was used for the ABS procedure as well.

The drag force and drag-induced moment (pitch) were computed, for all the TLP configurations tested in the wind tunnel experiment for wind approaching from the north, east, northeast, and northwest, using the ABS and DnV specifications. The results are compared with the experimental values in Tables 1 and 2. In Figs 19-21 the results are plotted for wind approaching from the North (0-degree). In a majority of the configurations, the DnV estimates are notably higher than the ABS estimates and the wind tunnel results. This is particularly true for the base case configurations. The ABS estimates are in almost every configuration lower than the corresponding DnV estimates. For the configuration in which most of the ancillary deck structure had been removed, the drag coefficient estimates were in good agreement with the specification societies' estimates. This is especially true for configurations 6,7 and 8 .

The estimated coefficients of drag-induced moment were lower than the corresponding wind tunnel measurements for configurations in which the drilling derricks had been removed but the helideck and the living quarters were still in place. In these configurations the flow-induced aerodynamic lift contributes to the pitching 


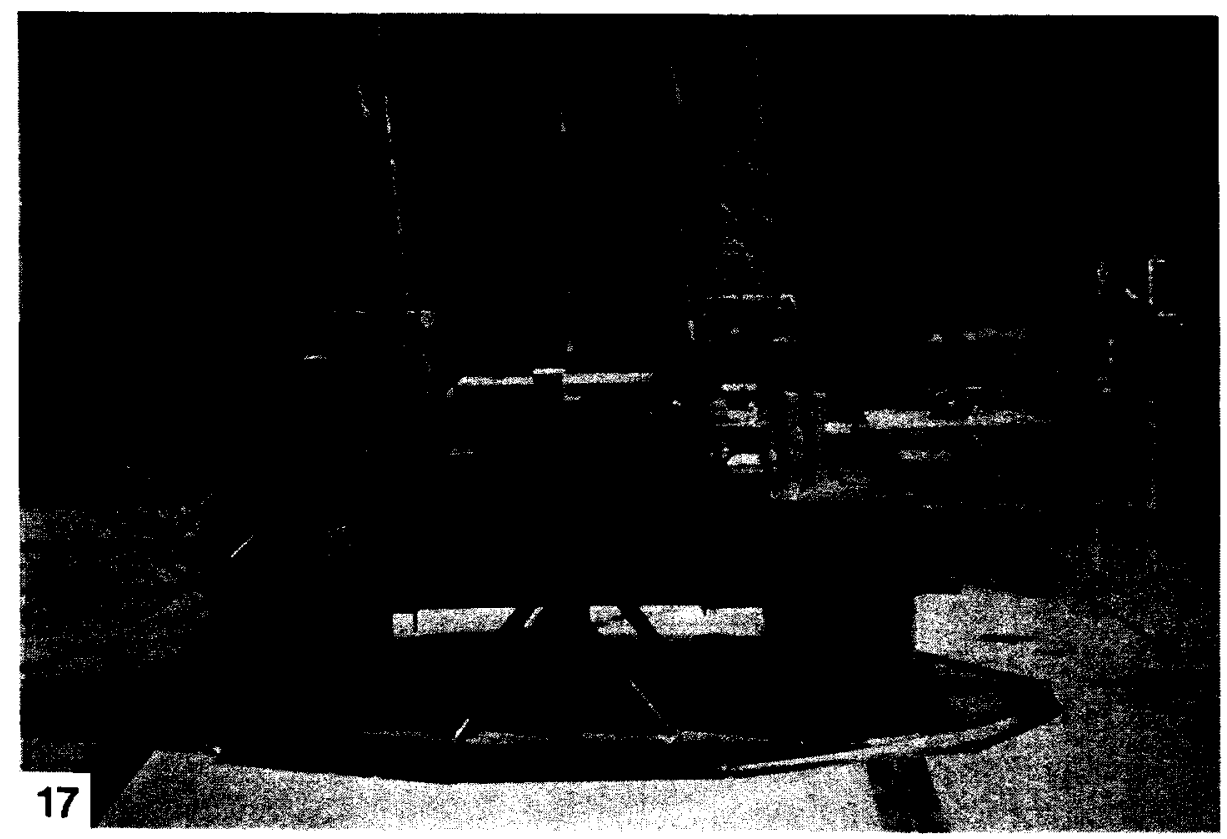

FIG. 17. Flow visualization-Separated flow over the helideck.

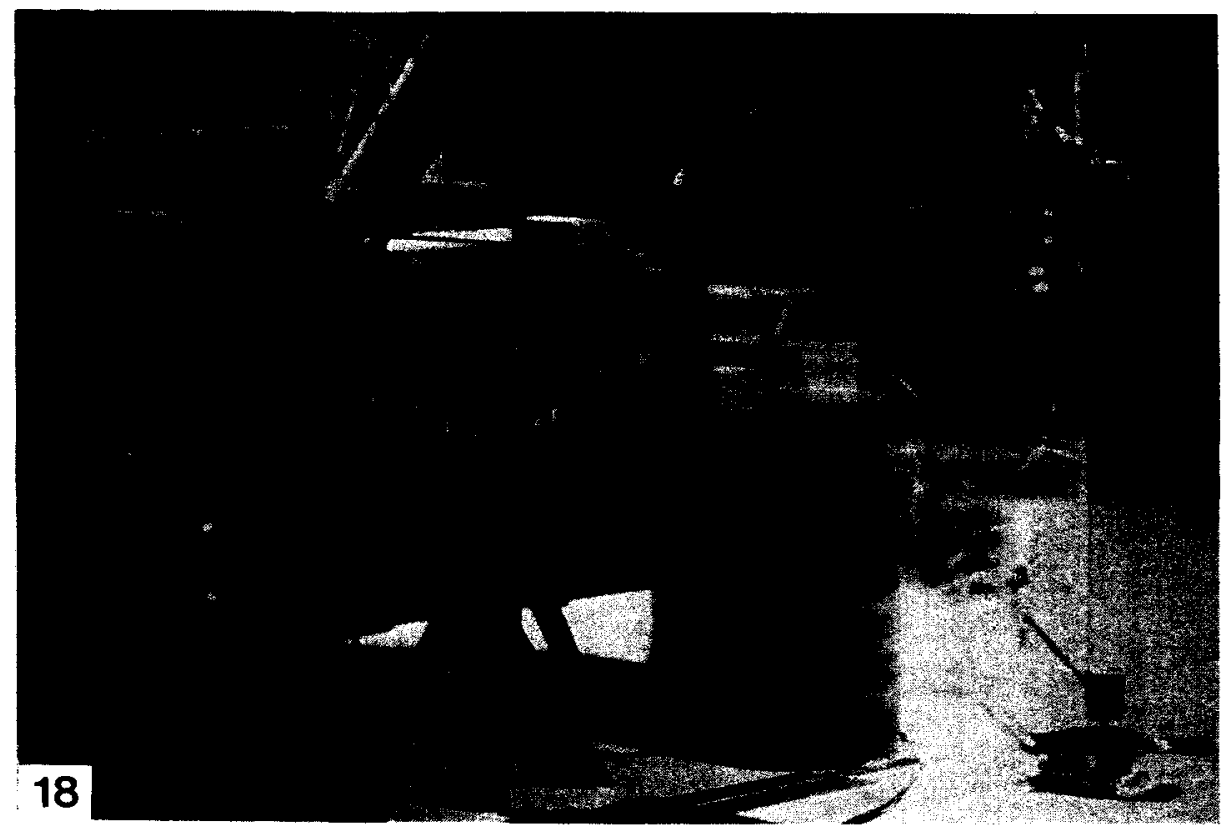

Fig. 18. Flow visualization-Wind approaching from 45 degrees. 

TABle 1. COMParison OF DRAG FORCE COEFFICIENTS

\begin{tabular}{|c|c|c|c|c|c|c|c|c|c|c|c|c|}
\hline \multirow[b]{2}{*}{$\begin{array}{l}\text { Configur- } \\
\text { ation }\end{array}$} & \multicolumn{12}{|c|}{ Wind direction } \\
\hline & DnV & $\begin{array}{c}N \\
\text { ABS }\end{array}$ & WT & DnV & $\begin{array}{c}\mathrm{E} \\
\mathrm{ABS}\end{array}$ & WT & DnV & $\begin{array}{l}\mathrm{NE} \\
\mathrm{ABS}\end{array}$ & WT & $\mathrm{DnV}$ & $\begin{array}{r}\text { NW } \\
\text { ABS }\end{array}$ & WT \\
\hline \multirow[t]{2}{*}{1} & 2.06 & 1.89 & 1.56 & 1.98 & 1.81 & 1.47 & 2.11 & 1.97 & 1.82 & 2.05 & 2.03 & 1.75 \\
\hline & \multicolumn{3}{|c|}{$\begin{array}{l}\text { Silhouette } \\
\text { Method } 1.98\end{array}$} & \multicolumn{3}{|c|}{$\begin{array}{l}\text { Silhouette } \\
\text { Method } 1.72\end{array}$} & \multicolumn{3}{|c|}{$\begin{array}{l}\text { Silhouette } \\
\text { Method 2.04 }\end{array}$} & \multicolumn{3}{|c|}{$\begin{array}{l}\text { Silhouette } \\
\text { Method } 2.13\end{array}$} \\
\hline 2 & 1.86 & 1.89 & 1.40 & 2.02 & 1.81 & 1.42 & 2.11 & 1.97 & 1.74 & 2.05 & 2.03 & 1.72 \\
\hline 3 & 1.66 & 1.59 & 1.34 & 1.62 & 1.53 & 1.36 & 1.76 & 1.66 & 1.55 & 1.69 & 1.72 & 1.47 \\
\hline 4 & 1.25 & 1.29 & 1.10 & 1.23 & 1.25 & 1.09 & 1.41 & 1.34 & 1.38 & 1.34 & 1.40 & 1.27 \\
\hline 5 & 1.03 & 1.06 & 0.93 & 0.96 & 0.99 & 0.87 & 1.16 & 1.09 & 1.04 & 1.10 & 1.15 & 1.08 \\
\hline 6 & 0.86 & 0.78 & 0.86 & 0.80 & 0.75 & 0.79 & 0.92 & 0.80 & 0.94 & 0.86 & 0.86 & 0.91 \\
\hline 7 & 0.77 & 0.72 & 0.80 & 0.77 & 0.72 & 0.79 & 0.83 & 0.74 & 0.98 & 0.76 & 0.80 & 0.84 \\
\hline 8 & 0.68 & 0.63 & 0.69 & 0.68 & 0.63 & 0.66 & 0.70 & 0.69 & 0.87 & 0.70 & 0.69 & 0.81 \\
\hline
\end{tabular}

TABLE 2. COMPARISON OF DRAG-INDUCED MOMENT COEFFICIENTS

\begin{tabular}{|c|c|c|c|c|c|c|c|c|c|c|c|c|}
\hline \multirow[b]{2}{*}{$\begin{array}{l}\text { Configur- } \\
\text { ation }\end{array}$} & \multicolumn{12}{|c|}{ Wind direction } \\
\hline & DnV & $\begin{array}{c}\mathrm{N} \\
\mathrm{ABS}\end{array}$ & WT & DnV & $\begin{array}{c}\mathrm{E} \\
\mathrm{ABS}\end{array}$ & WT & DnV & $\begin{array}{r}\text { NE } \\
\text { ABS }\end{array}$ & WT & DnV & $\begin{array}{r}\text { NW } \\
\text { ABS }\end{array}$ & WT \\
\hline 1 & 1.86 & 1.64 & 1.33 & 1.77 & 1.60 & 1.16 & 2.15 & 1.70 & 1.33 & 2.09 & 1.75 & 1.23 \\
\hline 2 & 1.62 & 1.64 & 1.16 & 1.85 & 1.60 & 1.15 & 2.15 & 1.70 & 1.25 & 2.09 & 1.75 & 1.23 \\
\hline 3 & 1.35 & 1.25 & 1.13 & 1.33 & 1.21 & 0.92 & 1.54 & 1.29 & 1.02 & 1.48 & 1.34 & 1.07 \\
\hline 4 & 0.82 & 0.85 & 0.89 & 0.81 & 0.83 & 0.74 & 0.93 & 0.88 & 0.79 & 0.87 & 0.93 & 0.73 \\
\hline 5 & 0.55 & 0.56 & 0.79 & 0.50 & 0.51 & 0.45 & 0.63 & 0.56 & 0.53 & 0.57 & 0.62 & 0.60 \\
\hline 6 & 0.43 & 0.37 & 0.76 & 0.38 & 0.35 & 0.38 & 0.47 & 0.37 & 0.45 & 0.41 & 0.42 & 0.48 \\
\hline 7 & 0.36 & 0.32 & 0.28 & 0.36 & 0.32 & 0.42 & 0.40 & 0.33 & 0.17 & 0.34 & 0.38 & 0.18 \\
\hline 8 & 0.28 & 0.24 & 0.14 & 0.28 & 0.24 & 0.26 & 0.28 & 0.27 & 0.08 & 0.28 & 0.27 & 0.08 \\
\hline
\end{tabular}

moment. As discussed earlier, the projected area approach fails to include this contribution which leads to the underprediction of the drag-induced moment. In configurations 7 and 8 , the removal of living quarters and helideck, eliminated the dominant source of flow-induced lift force that led to the original trend in the variation of predicted and measured coefficients.

The predicted and measured coefficients of the torque moment generally followed the trend observed earlier for the drag force, i.e. generally the predicted values being higher than the measured. However, the difference was not as prominent as that in the drag due to a relatively lower level of overall torsional moment acting on the platform. It is important to note that there may be a significant level of imbalance in the unsteady aerodynamic loading due to both the asymmetrical geometry of the platform and lack of spatial correlation of the random wind field over structural components that are well-separated.

A simplified approach was also used to estimate aerodynamic loads and was compared with other procedures for validation. This approach is primarily based on computing 


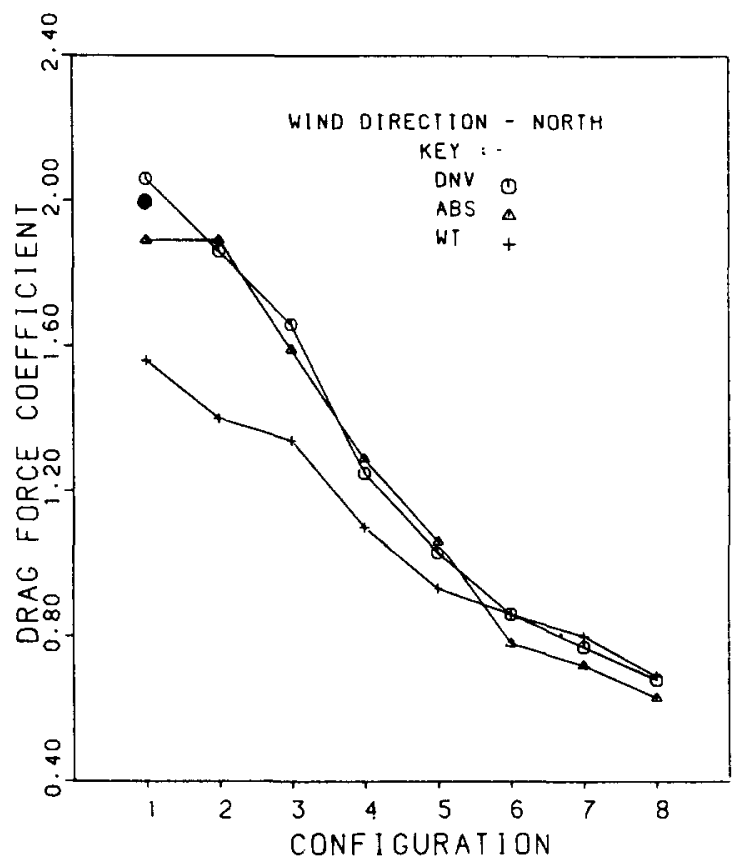

FiG. 19. Comparison of predicted and measured drag coefficients-Wind approaching from 0 degrees (• silhouette approach).

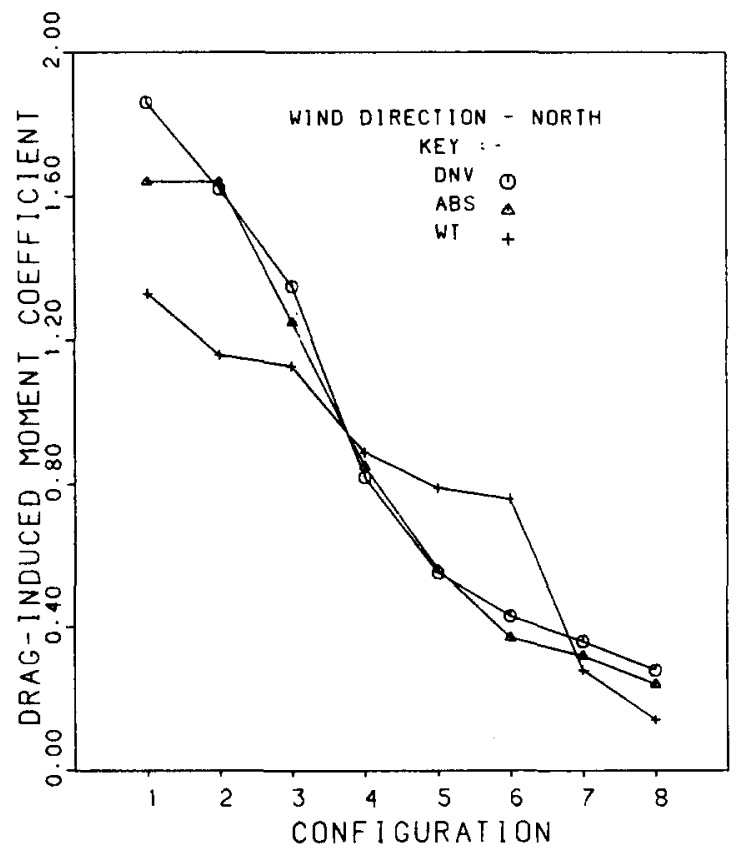

Fig. 20. Comparison of predicted and measured drag-induced moment coefficients—Wind approaching from 0 degrees. 


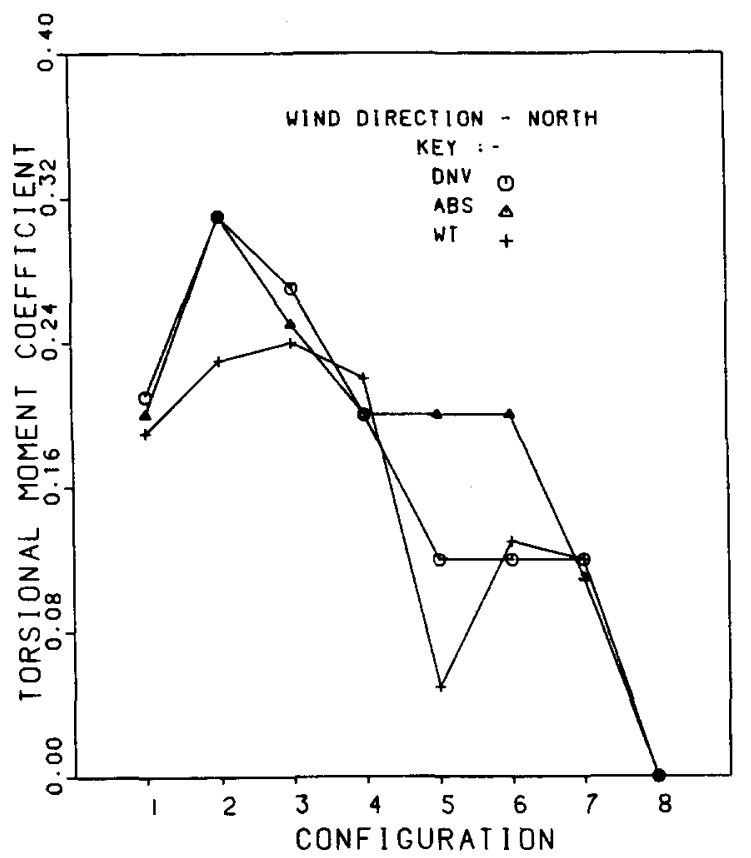

Fig. 21. Comparison of predicted and measured torsional moment coefficients-Wind approaching from 0 degrees.

TABle 3. COMPaRison OF TORSIONAL MOMENT COEFFICIENTS (YAW)

\begin{tabular}{|c|c|c|c|c|c|c|c|c|c|c|c|c|}
\hline \multirow[b]{2}{*}{$\begin{array}{l}\text { Configur- } \\
\text { ation }\end{array}$} & \multicolumn{12}{|c|}{ Wind direction } \\
\hline & DnV & $\stackrel{\mathbf{N}}{\mathrm{ABS}}$ & WT & DnV & $\begin{array}{c}E \\
\text { ABS }\end{array}$ & WT & DnV & $\begin{array}{r}\text { NE } \\
\text { ABS }\end{array}$ & WT & DnV & $\begin{array}{r}\text { NW } \\
\text { ABS }\end{array}$ & WT \\
\hline 1 & 0.21 & 0.20 & 0.19 & 0.09 & 0.08 & 0.06 & 0.17 & 0.22 & 0.27 & 0.12 & 0.14 & 0.066 \\
\hline 2 & 0.31 & 0.31 & 0.23 & 0.09 & 0.08 & 0.055 & 0.30 & 0.32 & 0.33 & 0.26 & 0.24 & 0.048 \\
\hline 3 & 0.27 & 0.25 & 0.24 & 0.30 & 0.23 & 0.09 & 0.43 & 0.40 & 0.36 & 0.02 & 0.23 & 0.05 \\
\hline 4 & 0.20 & 0.20 & 0.22 & 0.09 & 0.23 & 0.04 & 0.17 & 0.22 & 0.28 & 0.12 & 0.14 & 0.10 \\
\hline 5 & 0.12 & 0.20 & 0.05 & 0.09 & 0.23 & 0.04 & 0.12 & 0.22 & 0.12 & 0.08 & 0.14 & 0.07 \\
\hline 6 & 0.12 & 0.20 & 0.13 & 0.09 & 0.08 & 0.04 & 0.13 & $0: 14$ & 0.18 & 0.08 & 0.06 & 0.003 \\
\hline 7 & 0.12 & 0.11 & 0.12 & 0.12 & 0.11 & 0.05 & 0.22 & 0.20 & 0.12 & 0.0 & 0.0 & 0.063 \\
\hline 8 & 0.0 & 0.0 & 0.001 & 0.0 & 0.0 & 0.09 & 0.0 & 0.0 & 0.07 & 0.0 & 0.0 & 0.06 \\
\hline
\end{tabular}

the force acting on the silhouette of the structure. The silhouette is assigned a force coefficient and the area of the silhouette is multiplied by the force coefficient, dynamic pressure $\left(1 / 2 \rho U^{2}\right)$ and appropriate height coefficient to incorporate the variation in wind speed with height. This approach is computationally very expedient and eliminates the synthesis of forces associated with each major component of the platform as required by the projected area approach. The aerodynamic force and moment coefficients following this procedure were computed and reported for the base case configuration 
in Table 1 and Fig. 19. The results are in good agreement with the other two approaches and were evaluated with a fraction of the effort.

\section{CONCLUSIONS}

A wind tunnel investigation of the aerodynamic loads on a typical tension leg platform has led to the following major conclusions

(a) The current classification society procedures based on projected area approach tend to overestimate force and moment coefficients.

(b) Both aerodynamic load measurements and flow visualization experiments suggest that flow-induced lift forces over the helideck and living quarters contribute significantly to the drag-induced moment on the platform at the mean sea surface.

(c) Interference and proximity effects among various ancillary deck structures are notable and influence the aerodynamic force and moment coefficients.

(d) The drilling derricks introduce prominent wind load effects in terms of their contribution to the overall aerodynamic loads.

(e) The measured aerodynamic loads were insensitive to the range of Reynolds number encompassed in this study. The provision of discrete roughness on the cylindrical legs of the base case platform configuration in two different spatial arrangements did not influence the measured loads. This suggests that the stubby cylindrical legs abutted on one side onto dual-level deck structures, and the mean sea surface on the other end, are relatively less sensitive to the Reynolds number when exposed to very turbulent shear flows. On the other hand the complex vortical flow may render apparently successful technique, of utilizing surface roughness on isolated cylinders to simulate high Reynolds number flows, inapplicable for the cylindrical legs of a TLP. This insensitivity may also be attributed to the relatively low contribution of the cylindrical legs to the overall drag as a consequence of small frontal area near the mean sea surface that is exposed to the lower wind speeds.

(f) A wind tunnel investigation provides an accurate and practical means of evaluating steady wind load effects. Physical modeling of the structure facilitates an accurate representation of the interaction between the wind and structure, as well as the interference effects among various ancillary structures on the deck and flow induced loads.

(g) Flow visualization experiments provide a qualitative mapping of the aerodynamic environment around the platform and help to identify potentially troublesome and undesirable features such as intense turbulence and rapid variation of local velocities. Flow visualization also serves as a practical tool for managing flow around the platform to ensure minimum adverse flow conditions.

Acknowledgements-The support for this research was provided in part by the Chevron Corporation and the National Science Foundation Grant ECE8352223. Any opinions, findings, conclusions or recommendations expressed in this publication are those of the authors and do not necessarily reflect the views of the sponsors.

\section{REFERENCES}

ACHENBACH, E. 1968. Distribution of local pressure and skin friction around a circular cylinder in cross-flow up to $R_{e}=5 \times 10^{\circ}$. J. Fluid Mech. 34(4).

American Bureau of Shipping. 1980. Rules for Building and Classing Mobile Offshore Drilling Units. 
Cermak, J.E. 1971. Laboratory simulation of the atmospheric boundary layer. AIAA J. 9(9).

CORKE, T. et al. 1977. A new technique for introducing controlled sheets of smoke streaklines in wind tunnels. Proceedings of International Congress on Instrumentation in Aerospace Simulation Facilities, IEEE Publication, $77 \mathrm{CH} 1251-8$ AES.

DET NORSKE VERTTAS. 1982. Rules for the Design Construction and Inspection of Offshore Structures, Appendix B.

Kareem, A. 1980. Dynamic effects of wind on offshore structures. Proc. 12th Offshore Technology Conference, OTC 3764.

KAREEM, A. 1985. Structure of wind field over the ocean. International Workshop on Offshore Winds and Icing, Halifax, Nova Scotia, Atmospheric Environment Service of Canada.

Kareem, A. and Cheng, C-M. 1984. A crosswind response of towers and stacks of circular cross-section. Report No. UHCE 84-5, Department of Civil Engineering, University of Houston.

KAREEM, A. and Lu, P.C. 1985. A wind tunnel investigation of aerodynamic loads on a typical tension leg platform, Dept of Civil Engineering Report, No. UHCE 85-9, University of Houston.

KAREem, A., Lu, P.C. and He, T. 1985. Software for automated experimental control, data acquisition and reduction on a PDP-Micro 11, Dept of Civil Engineering Technical Report, No. UHCE 85-10, University of Houston.

KAREEM, A. et al. 1986. A wind tunnel investigation of aerodynamic loads on a typical tension leg platform, OTC 5173, Proceedings Offshore Technology Conference, Houston, TX.

MASKell, E.C. 1963. A theory of blockage effects on bluff bodies and stalled wings in a closed wind tunnel, RAE Aero Report 2685.

Melbourne, W.H. 1982. Wind Tunnel Blockage Effects and Corrections, Wind Tunnel Modeling for Civil Engineering Applications. Cambridge University Press, Cambridge.

Nakamura, Yo and TomonRai, Y. 1982. The effects of surface roughness on the flow past circular cylinder at high Reynolds number. J. Fluid Mech. 123.

NaumanN, A. and Quadflieg, H. 1972. Vortex generation on a cylindrical building and its simulation in wind tunnel, flow induced structural vibration. INTAM-IAHR Symposium, Karlsruhe.

Simiu, E. and Scanlan, R.H. 1978. Wind Effects on Structures, An Introduction to Wind Engineering. Wiley Interscience, New York.

SzechenY, E. 1975. Supercritical Reynolds number simulation for two-dimensional flow over circular cylinder. J. Fluid Mech. 70(3).

USGS. 1979. Outer Continental Shelf Platform Verification Program, USGS Conservation Division. 